\title{
LAS REDES SOCIALES EN MADRID Y LA CONGREGACIÓN DE SAN FERMÍN DE LOS NAVARROS, SIGLOS XVII Y XVIII ${ }^{1}$
}

\author{
Guillermo PÉreZ SARRión
}

Universidad de Zaragoza

RESUMEN: El crecimiento demográfico de Madrid desde fines del siglo XVI y su condición de sede de la corte y centro de recepción de las rentas de la aristocracia terrateniente, la Iglesia y el rey, generó importantes corrientes migratorias desde Castilla y el Norte peninsular y convirtió a la villa en un gran crisol social y el mayor centro político y financiero de la monarquía. Los inmigrantes, organizados en redes sociales, crearon hospitales y congregaciones para practicar la piedad y ayudarse mutuamente. La Congregación de San Fermín de los Navarros agrupó a los nacionales de dicho reino, que a pesar de no poseer la naturalidad castellana ocuparon puestos decisivos en la administración y las finanzas de la monarquía. La construcción de la iglesia confraternal muestra la relevancia económica y política de sus miembros. Su vida institucional permite conocer los frecuentes contactos de unas congregaciones con otras, y los lazos de vecindad geográfica, lengua y éxito social compartido que unieron a las redes de vascos y navarros, siempre cercanas pero distintas.

Palabras Clave: Redes sociales. Migraciones. Navarra. Madrid. Siglo XVIII.

ABSTRACT: From the end of 16th Century, Madrid, as the home of the court and the main recipient of the landed revenues of the monarchy, aristocracy and Church, rapidly increased in size and attracted buge migration, thereby becoming a significant

\section{ABREVIATURAS}

ACSFN $=$ Archivo de la Real Congregación de San Fermín de los Navarros, Madrid.

$\mathrm{NR}=$ Novísima recopilación de las leyes de España...

Nueva recopilación $\ldots=$ Recopilación de las leyes destos reynos becha ...

NRLRN = Novissima recopilacion de leyes del Reino de Navarra...

1 Este trabajo se ha realizado en el marco de los proyectos BHA 2003-00778 «Migraciones y movilidad social en el valle del Ebro, siglos XVI-XVIII» y HUM 2004-00537 «Absolutismo y mercado. La política del Estado, siglos XVII y XVII», financiados por el MCYT. Ha sido posible gracias a Jean-Pierre Dedieu, del Laboratoire de Recherches Historiques Rhône-Alpes (LARHRA) del Institut des Sciences de l'Homme, Lyon, que me permitió el acceso a la base de datos Fichoz y me ayudó en la introducción de datos, y de Lucrecia Raquel Enríquez Agrazar, de la Universidad Católica de Santiago de Chile, que colaboró en la tarea. Vaya para ambos mi mayor agradecimiento. 
consumption market and financial center. Those who migrated set up complex social networks as well as hospitals and brotherhoods for mutual help. One of those, the Congregacion de San Fermin de los Navarros, linked those coming from Navarre, who beld important positions in commerce, banking and royal bureaucracy through strong kinship and patronage networks. The building of a new church for the fraternity shows up the strong economic position of its members. Several internal debates point out how consistent the reciprocal relationship was between these brotherboods and the close but separate neighborboods fo the Navarrese and Basque communities in Madrid.

KEY WORDS: Social networks. Migrations. Navarre. Madrid. 18th Century.

La idea de que el llamado Antiguo Régimen tuvo un papel menor en cuestiones tales como el surgimiento del Estado moderno o del mercado nacional, está cambiando rápidamente. Sabemos con certeza que el mercado interior español estaba empezando a formarse ya en el siglo XVIII, e incluso a fines del siglo XVII en ciertas zonas, y que el desarrollo de la administración del Estado y los cuerpos de funcionarios que constituían su sustancia estaban sorprendentemente avanzados antes de la revolución liberal.

Este doble proceso puso en movimiento grandes cantidades de trabajo y capital. El trabajo fue aportado por olas migratorias de individuos que, con propósitos diversos, buscaron trabajo, fortuna y poder, y que al hacerlo fueron desarrollando redes sociales cada vez más extensas. Muchas de ellas confluían en Madrid o pasaban por allí. Quienes desde el siglo XVI emigraron a la capital lo hicieron huyendo de la pobreza, las guerras o la intolerancia religiosa, o buscando trabajo manual, oficios artesanales, negocios mercantiles y financieros e incluso poder político, o todo a la vez. Y al perseguir sus objetivos, además de extensas redes familiares y mercantiles crearon las congregaciones que aquí van a ser objeto de atención.

En cuanto al capital, sólo podía provenir de quienes lo tenían: la Iglesia, la aristocracia terrateniente y quienes hacían dinero con el tráfico comercial. Por lo menos desde fines del siglo XVII se fueron desarrollando en la península unas cuantas regiones económicas, y en este contexto la aparición de una aglomeración urbana como Madrid en el centro de la meseta castellana fue un hecho importante. La condición de sede permanente del rey, espacio social y centro de negociación y percepción de rentas de la aristocracia, la Iglesia y el rey mismo, otorgaron a la ciudad castellana, que era ya importante centro de consumo, un papel central en el desarrollo de la administración del Estado monárquico y en el tráfico y negociación de todo tipo de impuestos y rentas. Estos hechos, tan ignorados, convirtieron a la capital castellana, española, en el principal centro financiero de la monarquía.

Aquí se da noticia de una de las congregaciones que crearon las redes migratorias en Madrid, la Congregación de San Fermín de los Navarros, con el objetivo de conocer los rasgos básicos de su estructura y evolución institucional, quiénes fueron sus miembros, y cuáles fueron sus relaciones con otras congregaciones. No 
entraré a analizar otros aspectos básicos de su actividad tales como cuál fue la protección social que dio, qué redes sociales circularon por su seno, o qué cauces creó para impulsar y mantener la sociabilidad de sus miembros.

La congregación desplegó una actividad piadosa con los inmigrantes navarros, generalmente pobres o desfavorecidos. El análisis de qué personas giraban alrededor de cada caso o de cómo se organizaban los congregantes para conseguir los objetivos, mostrará que albergaba en su seno potentes redes de poder, las creadas por los inmigrantes viejos, muchos de cuyos miembros, organizados en redes familiares, mercantiles y administrativas, habían alcanzado gran influencia en los negocios de la Corte y en los aparatos administrativos y de poder que antes y después de la Guerra de Sucesión fueron desarrollando las administraciones de Austrias y Borbones. Entre 1684 y 1814, la congregación de San Fermín fue mucho más importante por lo que representaba, la poderosa comunidad navarra, que por lo que aparentemente fue, una más de las muchas asociaciones piadosas madrileñas de esos tiempos.

\section{EL MUNDO DE LAS CONFRATERNIDADES}

No obstante, las congregaciones de nación ${ }^{2}$ madrileñas eran sólo una mínima parte de una vida asociativa confraternal española y madrileña. En la zona de densidad más extrema, el norte de Castilla y León, en el caso conocido de Zamora las cofradías empezaron a desarrollarse en los siglos XIII y XIV; en 1400 había sólo 10 pero en las dos últimas décadas del siglo XIV empezaron a crecer y en la segunda mitad del siglo XVI había ya la enorme suma de 150 cofradías para una población de sólo 8.600 habitantes; todas eran muy pequeñas, de 30-40 individuos, y muchos vecinos pertenecían a más de una. Más de 100 de estas cofradías eran de gente que pertenecía a los oficios más bajos, y el hecho parece tener relación con el escaso desarrollo de los gremios: sólo escasamente dos docenas de oficios los tenían para entonces. La mayor parte, 125, tenían su sede en las nada menos que 30 parroquias de la ciudad y sólo 24 estaban ubicadas en conventos, santuarios y capillas ${ }^{3}$.

2 En este artículo los términos nación, comunidades nacionales, de nacionales, que los contemporáneos sin excepción utilizaban para referirse a ellos mismos, no tiene el significado político actual de ciudadanos de un Estado, sino un significado social. La formaban quienes compartían vínculos territoriales de vecindad, naturalidad, lengua, parentesco, linaje o devoción, o incluso quienes simplemente se consideraban adscritos a un grupo social o de poder que así se denominara. Tenía un significado polivalente que más que para definir el grupo propio servía para diferenciarlo de los demás.

3 A fines del siglo XVI Valladolid, con unos 13.000 habitantes, tenía unas 100 cofradías; y Toledo, con unos 60.000 habitantes, 143. Todo según FLYNN, Maureen: Sacred Charity. Confraternities and social welfare in Spain, 1400-1700, Houndmills, Macmillan, 1989, pp. 15-34. La densidad en Zamora era la mayor de España: en 1771 había una cofradía por cada 57 individuos, cuando la media española ese año era aproximadamente de una cofradía por cada 300 individuos, para un total de por lo menos 26.000 cofradías. Sobre ello véase el interesante mapa de Flynn, pp. 138-140. 
En Madrid la vida asociativa confraternal estuvo muy influida por la Contrarreforma. Fue intensa en los siglos XVI y XVII, y a lo largo del siglo XVIII aún creció más. A fines de siglo había centenares de cofradías ${ }^{4}$, confraternidades, congregaciones, hermandades, e instituciones piadosas similares, con sedes en todo tipo de iglesias, adscritas territorialmente a las parroquias respectivas. Estas instituciones se habían ido desarrollando en Madrid desde hacía siglos, pero sobre todo lo hicieron en los siglos XVII y XVIII's. El registro de la sala de gobierno del Consejo de Castilla para el siglo XVIII consigna entradas para al menos 135 cofradías y congregaciones no gremiales y 31 gremiales. La lista es muy incompleta ${ }^{6}$ : de hecho, fueron más.

Según Sánchez Madariaga en 1561, cuando la ciudad fue convertida en Corte, había unas 40 instituciones; pero entre 1339 y 1809 se llegaron a constituir unas 600, es decir que en dos siglos y medio se crearon unas 550 confraternidades nuevas. En las fuentes documentales disponibles se constata un crecimiento notable a partir de 1671; pero en realidad el ritmo de creación debió ser bastante constante a lo largo de todo el período, y acumulativo. Las cofradías nuevas no sustituían a las preexistentes, sino que se añadían, y muy pocas llegaron a desaparecer antes del fin del Antiguo Régimen ${ }^{7}$. Los cofrades podían pertenecer a más de una asociación, manteniendo actividades diferenciadas en

4 El término viene del latín confraternitas. En inglés es brotherbood y fraternity, en francés confrérie y confraternité, en italiano confraternitá. Todos indican confraternidad, significando tanto la institución como el tipo de lazo fraternal, familiar, que une a sus miembros: de ahí que cofradía en castellano equivale a confraternidad. Lo relativo a las cofradías, sustantivo para el que el castellano no tiene adjetivo derivado, puede calificarse como confraternal o congregacional.

En el Antiguo Régimen español las cofradías recibieron también otros nombres: cabildos (hasta principios del siglo XVII) congregaciones desde aproximadamente 1580; hermandades, y esclavitudes o congregaciones de esclavos (SÁNCHEZ MADARIAGA, E., Cofradías y sociabilidad en el Madrid del Antiguo Régimen, Madrid, UNAM, 1997, pp. 39-40). Las congregaciones, pues, eran simplemente un tipo de cofradías.

5 Las constituciones de las congregaciones madrileñas que he tenido ocasión de consultar (Congregación y Escuela de Cristo, de la Purificación, de San Fermín de los Navarros, de San Ignacio de Loyola) muestran que la aprobación dependía del arzobispo de Toledo, trámite para el que era necesario un informe del párroco a cuyo territorio correspondía la iglesia en la que la congregación iba a tener su sede: capilla, iglesia, convento, o la iglesia de la parroquia misma. Por un tiempo el rey no tuvo competencias, probablemente porque no eran de patronato real y el nombramiento de oficios no implicaba rentas, y por eso no hay noticia de ellas en los llamados libros de iglesia en que el rey y el Consejo de la Cámara de Castilla anotaban las resoluciones sobre los oficios eclesiásticos cuyo nombramiento correspondía al rey. Éste se ocupó de las congregaciones por lo menos desde 1755 - poco después del concordato de 1753 - y sus asuntos se llevaron en la sala de gobierno del Consejo de Castilla, lo que indica que para la monarquía fueron un asunto esencialmente gubernativo: eran «cuerpos políticos» o «cuerpos de nación», términos de la época.

6 Ya que no aparecen por lo menos las congregaciones de nacionales a que aquí aludo. AHN, Consejos, libro 2700.

7 La relación en Sánchez Madariaga: ob. cit., pp. 657-737 (apéndice 1); el análisis evolutivo conjunto en pp. 83-172. 
cada una; de media los fundadores solían ser unos 25 individuos, las menores podían tener menos de 50 miembros, las medianas entre 100 y 200, y las más grandes hasta 400 ó $500^{8}$.

La población de Madrid creció mucho, pero aún así las cofradías se multiplicaron tanto que crecieron en relación al número de habitantes: en 1561 tenía unos 20.000 habitantes y una cofradía por cada 500, pero en 1761 , con unos 150.000 , la proporción era aproximadamente de una por cada 250. Y eso que esta cantidad no incluye otras instituciones asociadas o dependientes de ellas, tales como hermandades, hospitales, conventos, parroquias, iglesias, capillas, ermitas, capellanías, fundaciones y otras obras pías.

Las cofradías, asociaciones religiosas de laicos, fueron adaptando su tarea a las necesidades sociales sin perder, aparentemente, su carácter original, como tantas otras instituciones del Antiguo Régimen europeo. Nacidas en la Edad Media, quedaron profundamente afectadas por la Reforma y la Contrarreforma y proliferaron en toda Europa en los siglos XVII y XVIII. En el caso de la monarquía hispánica, las de Madrid quedaron afectadas, además de por la Contrareforma católica, por el propio desarrollo de la ciudad como villa y corte, que atrajo inmigrantes como mano de obra y las élites del país. La organización eclesial fue originariamente parroquial, pero una vez que la Corte se instaló definitivamente en la ciudad, ésta se llenó de conventos que progresivamente entraron en competencia con las parroquias por conseguir que las cofradías se instalaran en ellos.

Desde el siglo XVI las confraternidades madrileñas se crearon a partir de todo tipo de formas de agrupación social, derivadas tanto del oficio como del estatus jurídico o social. Las hubo piadosas de caballeros, escuderos, labradores, mercaderes, agremiados de oficios de todo tipo; asistenciales de nobles y personajes prominentes, para el cuidado de enfermos, hospitales, pobres, peregrinos. Y como rasgo muy específico de Madrid, vinculado a la Corte, ya desde entonces hubo un florecimiento importante de cofradías de empleados miembros de la burocracia del rey y del municipio, y de las profesiones ligadas a ellos: oficiales de la administración, abogados, procuradores, alguaciles, correos. Con el tiempo se crearon colegios profesionales, como los importantes de abogados, con estatutos nuevos de $1761^{9}$, o el de escribanos reales y notarios ${ }^{10}$, que en algunos casos crearon cofradías; y hubo incluso una congregación de los funcionarios de un solo tribunal, la sala de Alcaldes de Casa y Corte del Consejo de Castilla, con ordenanzas desde $1627^{11}$.

En el siglo XVI y sobre todo en el XVII las cofradías conocidas como esclavitudes fueron agrupando ya a las élites cortesanas, al estilo de lo que se verá en

8 SÁnChez MADARIAGa: ob., cit., pp. 89-92.

9 AHN, Consejos (Consejo de Castilla), libro 5180; listas de miembros para 1785 y 1800 en ídem, libros 5013 y 5507.

${ }^{10}$ Una lista de los componentes en 1800 en AHN, Consejos (Consejo de Castilla), libro 5012.

${ }^{11}$ AHN, Consejos (Consejo de Castilla), libro 5481. 
la Congregación de San Fermín. Desde aproximadamente 1580, la Contrarreforma impulsó fuertemente las cofradías sacramentales dedicadas específicamente al Corpus Christi o al Santísimo Sacramento, es decir al culto eucarístico. Estas cofradías, de acuerdo con la función que se atribuía a las parroquias, fueron desarrollando también institutos públicos, tales como hermandades populares: desde fines del siglo XVII y sobre todo en el siglo XVIII fueron importantes en este sentido las llamadas hermandades de socorro, orientadas a la ayuda mutua ante la enfermedad, la muerte y la prisión ${ }^{12}$. Por ejemplo desde fines del siglo XVII, probablemente 1697, hubo una Hermandad del Camino, de San Antonio Abad, de alquiladores de mulas y literas, con sede en la parroquia de San Ginés ${ }^{13}$, vinculada al gremio de esparteros ${ }^{14}$, que tuvo ordenanzas en 1724 y privilegios confirmados en $1765^{15}$. Algunas de las cofradías asistenciales fueron fundadas para la asistencia de los nacionales extranjeros, no naturales del reino, tales como portugueses, italianos, franceses y flamencos ${ }^{16}$.

Así pues en los siglos XVII y XVIII hubo un desarrollo regular y creciente de cofradías. Una proporción creciente de las que se crearon se orientaron hacia la previsión social, hecho que hay que relacionar sin duda con el empeoramiento de las condiciones de vida (precios, alojamiento, trabajo) durante la centuria ilustrada. Las congregaciones tenían fines piadosos, sí; pero también, y de modo creciente, muchas de ellas, por sí o a través de instituciones asociadas (hospitales, colegios, fundaciones, capellanías, hermandades) abordaron objetivos sociales: de hecho funcionaron también como pequeñas asociaciones de asistencia sanitaria, cajas de pensiones, funerarias, lo que explica en parte por qué un cierto número pudieron ser muy pobres y estar compuestas por gentes de la más baja procedencia ${ }^{17}$. Funcionaron incluso como asociaciones gremiales y de carácter laboral.

12 Sobre todo esto véase, en general, SánChez MADARIAGA, caps. 1 a 6 ( pp. 27-430).

${ }^{13}$ La documentación en AHN, Consejos (Consejo de Castilla), libros 5023 y 5024 (libros y papeles, 1698-1726).

${ }_{14}$ AHN, Consejos (Consejo de Castilla), libro 5105 (1716).

15 AHN, Consejos (Consejo de Castilla), libros 5025 y 5026 respectivamente. Fenómenos similares debieron tener lugar en otras ciudades: en Barcelona hubo un gremio de alquiladores de mulas en Barcelona, con ordenaciones de 1765; AHN, Consejos (Consejo de Castilla), libro 5462. La documentación se conserva en el Instituto Municipal de Historia de Barcelona, ha sido estudiada por Assumpta Musset. En Valencia también hubo un gremio de trajineros con ordenanzas de 1778; AHN, Consejos (Consejo de Castilla), libro 5167.

16 SÁnCheZ Madariaga: ob., cit., pp. 111-113 y 117.

17 Por ejemplo en 1776 funcionaba desde 1771 una Congregación de Nuestra Señora del Pilar de Zaragoza, sin ordenanzas aprobadas, con una treintena de congregantes, que veneraba la imagen de la virgen en un humilladero en la calle Jardines. Su fin era

« (...) el culto a Maria Santísima y socorrer al necesitado, (...) todos los que se alistan en estas congregaciones no son otros que unos pobres menestrales, sirvientes y jornaleros que solo ganan de comer el día que trabajan; pero en llegando a caer en una cama se ven precisados a irse al santo hospital dejando por lo regular a las mujeres e hijos 
Sánchez Madariaga nos descubre esta polivalencia funcional, mostrando por ejemplo cómo ya en el siglo XVII en Madrid se crearon cofradías que pretendían crear luego gremios (caso de oficios mecánicos no agremiados, infames o viles y poco cualificados: sepultureros, comediantes, boteros, tablajeros); sustituirlos o partirlos (cofradías de maestros y oficiales), y formar «ligas y monipodios», es decir, monopolios de oficio sobre ciertas actividades: aguadores, traperos, apeadores de carbón, esportilleros, los ciegos por la venta de ciertos papeles públicos e incluso los pobres «auténticos» por el derecho a mendigar ${ }^{18}$. Porque hubo gremios mayores y también menores, como el de los herreros de grueso, con ordenanzas de $1760^{19}$, posiblemente relacionado con los vizcaínos. Es decir, que de hecho algunas cofradías fueron auténticos pequeños grupos de presión laboral: agrupaciones laborales con funciones sindicales además de las meramente asistenciales.

La extraordinaria floración de confraternidades, que tanto suele pasarse por alto en el análisis social, tuvo gran repercusión social y económica en las parroquias, conventos e iglesias que les dieron acogida y les cobraban estipendios, alquileres y servicios religiosos de todo tipo. Los cofrades tejieron densas mallas atomizadas que abarcaban la sociedad entera; formaron espacios sociales donde los individuos pudieron entablar relaciones y constituyeron instituciones que daban imagen y voz a los grupos sociales de todo tipo (profesionales, de gremio, de clase, de condición social, de élite, marginados) convirtiéndolos en interlocutores con la Iglesia, el poder político y otros grupos sociales. Y quienes migraron a Madrid también crearon cofradías, como hacían los demás colectivos.

en un conocido desamparo, agregándose a esto que otros llevados de que tienen bienes no se quieren ir al hospital, y por esta causa se ven precisados a irse deshaciendo de ellos, malbaratándolos y dándolos a menor precio para remediar sus males, al cabo de los cuales suelen fallecer sin tener medios para poder siquiera poder comprarles un hábito que poner al cadáver (...)».

La congregación pagaba 10 reales de vellón al día para médico hasta 36 días, en casa o en hospital, y gastos de entierro. El fiscal criticó la ubicación, una calle «donde es regular se ejecutan algunas operaciones nada decentes», y sugirió que se fuera a una parroquia, se incorporara a otra del mismo nombre o se disolviera. De diversos documentos, 1776, AHN, Consejos (Consejo de Castilla, sala de Alcaldes de Casa y Corte), libro 1364, ff. 800-821.

En cambio en 1786, en el convento de San Norberto de canónigos regulares premonstratenses, circunscripción de la parroquia de San Martín, se fundaba otra nueva congregación de Nuestra Señora del Pilar compuesta por miembros de procedencia social probablemente muy distinta: el hermano mayor y protector del convento era el duque de Benavente, y su esposa era la camarera mayor. De diversos documentos, AHN, Consejos (Consejo de Castilla, sala de alcaldes de Casa y Corte), libro 1375, ff. 1190-1234. En 1796 se estaba intentando fundar otra del mismo nombre en la iglesia de San Cayetano; AHN, Consejos (Consejo de Castilla, sala de gobierno), leg. 1690.

18 SÁNCHEZ MADARIAGA: ob., cit., pp. 140-142.

19 AHN, Consejos (Consejo de Castilla), libro 5481. 


\section{LAS CONGREGACIONES DE NACIONALES EN MADRID}

Las corrientes migratorias que formaron la población de Madrid desde el siglo XVI, tanto las mayoritarias: castellanos — sobre todo-, gallegos, asturianos y «cántabros» — vascos, navarros y riojanos-, como las minoritarias, compuestas por diásporas de mercaderes y financieros extranjeros, organizaron congregaciones de nacionales, cofradías piadosas cuyo objetivo inicial era fomentar la devoción a un santo patrón de la región de procedencia. Algunas permanecieron alojadas en parroquias o conventos; otras muy pocas, construyeron iglesias propias; otras más erigieron hospitales para acoger a los paisanos que llegaban. En algún caso las comunidades migratorias crearon directamente hospitales sin congregación piadosa alguna asociada. Los hospitales, construidos desde el siglo $\mathrm{XVI}$, eran casas de acogida y centros de curación para los nacionales llegados o residentes; sólo a mediados del siglo XVIII, con Carlos III, los ilustrados plantearon construir un hospital general en Madrid. En esto lo que sucedió allí no fue muy distinto de lo que también pasó en otras capitales, como Londres o París, y en otras ciudades de la monarquía como Sevilla o Cádiz, donde también hubo comunidades de extranjeros agrupadas en cofradías y hospitales, como se ha destacado recientemente a propósito de las asociaciones de flamencos ${ }^{20}$. Los propios españoles hicieron lo mismo allí donde su presencia fue significativa, como es el caso de la cofradía de la Santísima Resurrección, fundada en 1579 en la iglesia de Santiago de los Españoles en Roma, —a la que posteriormente se añadió hospital ${ }^{21}$, que en 1684 dependía de la embajada española ${ }^{22}$.

Sabemos poco de estas confraternidades que tanto estimularon la sociabilidad, los lazos de paisanaje, el intercambio de información, y el apoyo mutuo. El cuadro que sigue es una lista de las que hubo en Madrid.

${ }^{20}$ CRESPO SOLANA, Ana: «El patronato de la nación flamenca gaditana en los siglos XVII y XVIII», en Studia Histórica. Historia Moderna, nº. 24, pp. 310 y passim, con abundante bibliografía. Sobre el hospital de San Andrés de los Flamencos de Madrid véase también Vidal GaLACHE, Florentina y Vidal Galache, Benicia:, Historia del Hospital de San Andrés de los Flamencos, 15941994, Madrid, Fundación Carlos de Amberes, 1996.

${ }_{21}$ Dandelet, Thomas J.: La Roma española (1500-1700), Barcelona, Crítica, 2002, pp. 140154 y passim.

22 «La Congregación o Archiconfraternidad de la Santísima Resurrección, de toda la nación española, que es sita en mi Hospital Real de Santiago de los Españoles de esa Corte de Roma», de protección real, hacía años que no tenía gobernador ni oficiales, ni celebraba asambleas generales; dependía del agente general del rey en la embajada de Roma. La referencia en Reales Órdenes de 25-V, 25-VI y 20-IX-1684; AHN, Consejos (Consejo de la Cámara [de Castilla]), libro 38, ff. 61$62,107-107 v$ y $129-131$. 
CUADRO. COFRADÍAS Y CONGREGACIONES DE NACIONALES

EN MADRID, SIGLOS XVI-XVIII

\begin{tabular}{|c|c|c|}
\hline FUNDACIÓN & ADVOCACIÓN & Miembros \\
\hline \multicolumn{3}{|l|}{ Países europeos } \\
\hline 1581 & san Luis Rey de Francia & franceses \\
\hline 1616 & san Luis (hospital) & franceses \\
\hline c. 1598 & san Pedro & italianos \\
\hline 1579 & san Pedro y san Pablo (hospital) & italianos \\
\hline 1605 & san Andrés & flamencos (arqueros) \\
\hline 1626 & san Andrés (hospital) & italianos \\
\hline 1606 & san Antonio de Padua & portugueses \\
\hline 1626 & san Antonio (hospital) & portugueses ${ }^{23}$ \\
\hline 1635 & san Patricio (hospital) & irlandeses \\
\hline c. 1650 & ¿? (hospital) & escoceses \\
\hline \multicolumn{3}{|c|}{ «Naciones» de la Corona de Castilla (zona cantábrica) } \\
\hline 1684 & san Fermín & navarros \\
\hline 1715 & san Ignacio de Loyola & «cántabros», «vizcaínos» o vascos \\
\hline 1723 & Nuestra Señora de Valvanera & riojanos \\
\hline 1740 & Santiago & gallegos \\
\hline 1743 & Nuestra Señora de Covadonga & asturianos \\
\hline \multicolumn{3}{|c|}{ «Naciones» de la Corona de Castilla (resto, por orden territorial, de norte a sur) } \\
\hline 1727 & santo Toribio Alonso Mogrovejo & castellanos y leoneses \\
\hline 1732 & Santísimo Cristo de Burgos & arzobispado de Burgos \\
\hline 1752 & Nuestra Señora de la Bien Aparecida & montaña de Burgos \\
\hline 1748 & san Julián & obispado de Cuenca \\
\hline 1749 & santa Librada & obispado de Sigüenza \\
\hline 1750 & santo Tomás de Villanueva & manchegos 24 \\
\hline 1751 & san Dámaso, san Isidro ... & madrileños \\
\hline 1793 & San Ildefonso y santa Casilda & toledanos \\
\hline antes de 1763 & san Fernando & andaluces \\
\hline 1743 & $\begin{array}{l}\text { Nuestra Señora de Guadalupe de Méji- } \\
\text { co naturales y empleados en Indias }\end{array}$ & \\
\hline
\end{tabular}




\begin{tabular}{lll}
\hline FUNDACIÓN & ADVOCACIÓN & MiEMBROS \\
\hline «Naciones» de la & Corona de Aragón & \\
161625 & Nuestra Señora de Montserrat & catalanes («aragoneses») \\
antes de 1745 & Nuestra Señora del Pilar & aragoneses \\
antes de 1746 & Nuestra Señora de Montserrat (hospital) & «aragoneses»26 \\
1745 & Nuestra Señora de los Desamparados & valencianos \\
\hline
\end{tabular}

Fuente: a partir de los datos de Sánchez Madariaga (1997, p. 165), quien se basó en una encuesta de 1809 (original en AGS, Gracia y Justicia, leg. 1270) que completó con información adicional. Una lista completa de todas las confraternidades de Madrid en ídem, apéndice 1, pp. 657-737.

La información de la autora la he completado o en su caso rectificado con mis propios datos, de los que doy detalle a lo largo del artículo. He incluido los hospitales, pero no otras fundaciones dependientes de o promovidas por las congregaciones, tales como hermandades de socorro, iglesias, colegios, o entidades paralelas.

El cuadro muestra que llegó a haber diez confraternidades de extranjeros (para ser precisos: de naturales no castellanos), sumando congregaciones y hospitales, y hasta 19 de naturales españoles. El primer hecho destacable que se observa es que las cofradías de los que no eran naturales de reinos de la Corona de Castilla son las más antiguas. También eran tempranas las de los naturales de reinos de la Corona de Aragón: aragoneses, catalanes, mallorquines y valencianos, que inicialmente se agruparon en una sola congregación bajo la advocación de la patrona de Cataluña. La situación jurídica de quienes no eran naturales castellanos cambió radicalmente con la supresión de los fueros en la Corona de Aragón (1707-1714) y una resolución a consulta del Consejo ${ }^{27}$ de 1-X-1721 que de hecho fusionó la naturalidad en toda la monarquía, prescindiendo de las cortes pero no de quienes las componían ${ }^{28}$. Antes de ese momento también se crearon las congregaciones de navarros - 1684- y vascos - 1715-, que tenían estatus jurídico diferenciado dentro de la Corona de Castilla, Esto pudo influir en la creación, pero también - y yo diría que sobre todo- pesó en esto su poderosa posición funcionarial dentro de la monarquía.

Las demás congregaciones, todas de nacionales castellanos, se crearon en el siglo XVIII. Por fuerza, imitaron a las anteriores. Formaron confraternidades a partir de entidades que en algunos casos tenían significado histórico y político, pero en otros no: obispados (Burgos, Sigüenza, Cuenca), una provincia (Toledo),

25 Según Sánchez Madariaga fue fundada en 1797.

${ }^{26}$ El hospital ese año, primero en que se tiene constancia de él, aparece mencionado como el que acogía a los «aragoneses» de la Corona de Aragón (es decir: aragoneses, catalanes, valencianos y mallorquines), y no sólo a los catalanes. Castilla.

${ }^{27}$ El texto no indica cuál es: puede ser el Consejo de Castilla o el Consejo de la Cámara de ${ }^{28}$ NR, lib. I, tít. XIV, ley VI, nota 4 -I, p. 110—. 
o una simple zona geográfica (La Mancha, las montañas de Burgos). También resulta significativo que las congregaciones de aragoneses y valencianos se desgajaran de la de nacionales de la Corona de Aragón en el mismo momento, 1746, lo que apunta a una decisión conjunta tomada en circunstancias concretas.

¿Por qué y para qué se crearon estas instituciones de nacionales? Las aparecidas en los siglos XVI y XVII tuvieron la misma razón de ser: fomentar un vínculo de unión en torno a la advocación de un santo patrón y la protección asociativa a individuos que de hecho no eran naturales castellanos. El caso de las de navarros y vascos fue distinto porque — como veremos - no eran exactamente castellanos como los otros y porque a este factor de devoción y protección se añadió el prestigio social. En cuanto a todas las demás, creadas en el siglo XVIII, sin descartar factores de refuerzo de la autoidentidad en el melting pot madrileño, parece claro que, como durante esa centuria las condiciones de vida empeoraron en Madrid, los emigrantes castellanos, como tantos otros grupos sociales, fueron creando instituciones que en algún caso fueron sobre todo expresión de un grupo de poder — los riojanos y quizás también los aragoneses_-, y en el resto, la mayoría, cumplieron funciones de ayuda mutua y previsión social.

Los extranjeros relacionados con la actividad de la Monarquía española en los extensos territorios europeos desde el siglo XVI, constituyeron comunidades nacionales en Madrid desde muy pronto: de ellos hay noticias de detalle diverso $^{29}$. Dejando aparte a los franceses, los más numerosos, que se mencionan abajo, de los territorios de la monarquía hispánica hubo otras cinco comunidades. En 1605 por fundación particular de un flamenco vecino de Madrid, Carlos de Amberes, se creó el Hospital de San Andrés de los Flamencos en Madrid $^{30}$. Antes, en 1579, se fundó un Hospital de San Pedro y San Pablo de los Italianos $^{31}$; su iglesia aún subsistía por lo menos en 1932. En 1626 se fundó un Hospital de San Antonio de los Portugueses, que en 1687 pasó a serlo de los Alemanes; desde 1617 albergó la Hermandad del Refugio, que aún subsistía en $1965^{32}$. También hubo instituciones piadosas de las comunidades de católicos de Gran Bretaña, el gran enemigo protestante: un Hospital de San Patricio

29 Las noticias que siguen se extraen básicamente de SAGüÉs AzCONA, Pío: La Real Congregación de San Fermín de los Navarros en Madrid (1683-1961), Madrid, 1965 y del mapa de TeXeIRA, Pedro (1656), Topographia de la villa de Madrid. Descrita por... Año 1656, Antwerpen, Salomon Saury 1656, reedición facsímil, Madrid, Ayuntamiento, 1943, 20 hojas, donde se localizan las sedes de algunas de estas instituciones en las láminas LXVI (italianos), LXVII (portugueses) LXIX («aragoneses» de la Corona de Aragón), LXX (franceses), LXXI (flamencos) y LXXII (escoceses). La relación de edificios existentes está en lámina XVI.

30 Véase Crespo SolanA, ob. cit, p. 310.

31 En él tuvo sede una Congregación y Escuela de Cristo, adscrita a la parroquia de San Ginés, con constituciones de 1727 y ordenanzas de 1776, que no parece que fuera sólo de italianos; Constituciones de la congregación y escuela de Cristo en el hospital de los italianos en Madrid, AHN, Consejos (Consejo de la Cámara [de Castilla]), libros 5346 y también 5375 y 5376.

32 Hermandad «que todavía subsiste», SAGÜÉS AZCONA, ob. cit. 
de los Irlandeses fue fundado en $1635^{33}$, y a mediados del siglo XVII funcionaba también un Hospital de los Escoceses.

Sabemos poco aún de las congregaciones de naturales castellanos, que no van a ser objeto de atención salvo las que se mencionarán más abajo. Algunas fueron muy pobres, como la de los asturianos, cuyos congregantes no tenían miembros de la nobleza, y nutrían oficios como los de aguadores o mozos de cuerda, o la de Sigüenza ${ }^{34}$. Los «aragoneses», término que en los textos de la época con frecuencia servía para referirse a los naturales de los reinos de la Corona de Aragón: Aragón, Cataluña, Mallorca y Valencia ${ }^{35}$, tuvieron desde 1616 la congregación de Nuestra Señora de Montserrat ${ }^{36}$. En 1745 se crearon dos congregaciones de aragoneses (del reino de Aragón: Nuestra Señora del Pilar) y valencianos (Nuestra Señora de los Desamparados) que se desgajaron de la anterior.

Quedan cuatro comunidades más, a las que aquí concederé más importancia, todas de gente que llegó a Madrid desde el norte: franceses, vascos, navarros y riojanos. En 1581 los franceses en Madrid fundaron la congregación de San Luis Rey de Francia, y en 1613 se fundó el hospital de San Luis de los Franceses para los miembros de esta comunidad ${ }^{37}$ en Madrid. Eran tiempos de guerras de religión y de emigración de franceses católicos. En cuanto a las otras tres comunidades, españolas, los navarros, que son el objeto de atención en este artículo, fundaron la Real Congregación de San Fermín de los Navarros en el convento de franciscanos mínimos de San Francisco de Paula, también llamado de la Victoria, en $1683^{38}$. En 1715, 32 años después que los navarros y a imitación suya, se

33 Había también una iglesia y Colegio de San Patricio de los Irlandeses, que desde 1727 albergó una Congregación de María Santísima de la Purificación, presidida por el propio rector del colegio. Los 17 fundadores no parece que fueran irlandeses sino españoles, vinculados probablemente por relación personal. Las constituciones en AHN, Consejos (Consejo de la Cámara [de Castilla]), libro 5403.

34 SÁnChez MAdariaga: ob. cit., pp. 164-166.

35 Desde Carlos I de Gante su rey era el mismo que el de la Corona de Castilla. Sus naturalidades respectivas no fueron equiparadas a la castellana hasta 1721, como se acaba de indicar arriba.

36 También había en Madrid un monasterio de Nuestra Señora de Montserrat, fundado en tiempos de Felipe IV; una referencia en AHN, Consejos (Consejo de la Cámara [de Castilla]), libro 85, ff. 60v-61.

${ }^{37}$ Hay algunos estudios sobre él: ver Humphry, F.: Histoire de Saint-Louis des Français à Madrid, Bordeaux, 1854 y más recientemente Duroux, Rose: «Le voyageur et l'Hôpital. Du Massif Central à l'Hôpital Saint-Louis-des-Français de Madrid, 1617-1935», en Annales de Démographie Historique, no 84 (1994), pp. 261-276; «Entre archaïsme et modernité: les migrations du Massif central au XIX siècle», en René LebOUTTE (ed.): Migrations et migrants dans une perspective historique. Permanences et innovations, Bruxelles, P.I.E.-Peter Lang, 1977 (International conference proceedings, European Forum 1997-1998); «Estrategias patrimoniales excluyentes. Un caso francés», en Hispania, LX/1, núm. 204 (2000), pp. 315-330; «Migrants et Corporations. Corporations «molles», corporations «dures» (XVIII et XIX siècles, Auvergne/ Espagne)», Comunicación presentada a la International Commission on Historical Demography, $19^{\circ}$ Congreso Internacional de Ciencias Históricas, Oslo, 2000, inédito. Tenía censos y capellanías, y recibió una casa en la calle de Fuencarral el 3-II-1689; la escritura en AHN, Clero, leg. 3956.

38 Como veremos, en 1685 la congregación se trasladó al convento de la Trinidad (trinitarios calzados), al comienzo de la calle de Atocha, y en 1746, tras comprar la finca y antiguo palacio del 
fundó la «Real Congregación Nacional de los hijos y naturales de las muy nobles y muy leales Provincias del Señorío de Vizcaya, Guipúzcoa y Álava», también conocida con el menos complicado nombre de Congregación de San Ignacio de Loyola, con constituciones casi copiadas de las de los navarros ${ }^{39}$. En el siglo XVIII los paisanos procedentes de las provincias de Vizcaya, Guipúzcoa y Álava se reunían regularmente en ella ${ }^{40}$.

Las cofradías de navarros y vascos agruparon a la élite funcionarial y mercantil de esta procedencia, y 30 años después de que apareciera la vasca, los riojanos crearon la congregación de Nuestra Señora de Valvanera, de castellanos de la Rioja ${ }^{41}$. Tuvo un perfil social muy parecido al de la navarra y la vasca: fue creada por el marqués de Ensenada, que en esos años creó un poderoso grupo de poder político formado mayoritariamente por compatriotas. También los aragoneses formaron otro grupo de poder político en Madrid por entonces, y hay razones para pensar que ello tuvo que ver con la creación de la congregación de Nuestra Señora del Pilar.

La mayoría de las congregaciones de nacionales en Madrid son poco conocidas: hoy apenas podemos decir de ellas que existieron, y puede que nunca lleguemos a saber mucho más de ellas. Pero ello no debería ser obstáculo para preguntarse por qué surgieron, para qué servían realmente, cuál fue su composición y su actividad social, política y cultural. Todas ellas eran expresión de los grupos migratorios que habían construido Madrid como capital, Corte real, centro financiero y crisol social. El análisis individual de algunas dará pautas firmes para conocer cómo funcionaban las demás, y cómo debe interpretarse en términos históricos este mundo de congregaciones de nacionales que agrupaban a los migrantes que, organizados en redes, tuvieron éxito diverso en la competición por conseguir trabajo y poder.

conde de Monterrey, construyó una iglesia adosada «al salón del Prado». Finalmente en 1884 la iglesia y la congregación se trasladaron de nuevo a la calle Eduardo Dato, hasta hoy. Hay algunas publicaciones de carácter institucional sobre la sociedad: ademas de la ya citada de SAGÜES AZCONA, LizARZa Inda, Francisco Javier de: Real Congregación de San Miguel de los Navarros. Historia abreviada, Madrid, 1999, y para el patrimonio artístico RODRÍGUEZ GuTIÉRREZ DE CEVALLOS, Alfonso: «La Real Congregación de San Fermín de los Navarros», en Juan de Goyeneche y su tiempo, Pamplona, Gobierno de Navarra, 1999, pp. 137-169.

39 En 1715 la congregación se instaló en el convento de agustinos de San Felipe el Real, en la calle Mayor, y en 1767 se trasladó al antiguo Colegio de los Jesuitas expulsados, en la calle del Príncipe, esquina al paseo del Prado. Derribada a fines del siglo XIX, la congregación construyó una iglesia y sede en la calle Echegaray, donde hoy sigue. Los datos en SAGÜÉs: ob. cit., pp. 52-56 y 164-165 y RODRíGUEZ DE CEVALlOS: ob. cit., p. 145.

${ }^{40}$ El dato en BARRENECHEA, José Manuel: «Estudio preliminar», en Moral y economía en el siglo XVIII. Antología de textos sobre la usura: Zubiaur, Calatayud, los Cinco Gremios Mayores y Uría Nafarrondo, Vitoria, Gobierno Vasco, 1995, pp. XIII-CIV, p. LXXIII.

${ }^{41}$ GonZÁlez CAIZÁN, Cristina: «La cofradía de Valvanera. Riojanos en Madrid (1723-1782)», en Monarcas, ministros y Corte. La España de Felipe V y Fernando VI. Códices, Jaén 2002, en prensa.. El archivo de la congregación de los riojanos se conserva en el de la parroquia de San Ginés de Madrid; SÁNCHEZ MADARIAGA: ob. cit., p. 166. Ha sido consultado por ambas autoras. 
Los fines principales de las congregaciones de comunidades nacionales o de nacionales en Madrid fueron la devoción a un santo patrón, que identificaba a sus miembros, y la asistencia caritativa a los inmigrantes en hospitales, de acuerdo con una cultura identitaria no excluyente. Esto mismo sucedió con los navarros, los cuales aludieron en repetidas ocasiones a que la congregación al formarse no estaba sino emulando a los nacionales de la Corona de Aragón: aragoneses, catalanes y valencianos, que ya habían fundado antes otra congregación. Y cuando en 1732 los «cántabros» (vascos) y navarros, que en Nueva España se habían agrupado en la cofradía de Nuestra Señora de Aránzazu, decidieron fundar un colegio lo llamaron de San Ignacio de Loyola para que acogiera niños y viudas «de españoles» ${ }^{42}$. La identidad propia no excluía otras, y se creaba o reforzaba sobre todo en el contacto con ellas cuando se estaba fuera de la comunidad, lengua o territorio propios.

Así pues la congregación de San Fermín fue una más de las muchas que se fundaron, y se debió crear copiando el modelo de las de no naturales castellanos que desde hacía tiempo existían en Madrid. Hay sin embargo características que la hicieron especial y en cierto modo única en el universo de las cofradías madrileñas: era de nacionales no castellanos pero cuya naturalidad era equivalente a la castellana; reunió a un grupo de gente que entonces estaba triunfando en la política y el comercio en el seno de la monarquía; y constituyó una referencia para las demás cofradías de nacionales que, en nuevas circunstancias políticas, se crearon en el siglo XVIII. Esto se verá en los epígrafes que siguen, en que se analizan sucesivamente su actividad institucional, su composición social, la identidad de sus miembros, su actividad económica y sus relaciones con algunas otras congregaciones de nacionales.

\section{LA ACTIVIDAD INSTITUCIONAL}

La asamblea constitutiva de la congregación se celebró el 7-VII-1683, festividad de San Fermín. La actividad institucional oficial se canalizó a través del instrumento de gobierno básico, las juntas generales y particulares de congregantes $^{43}$, cuyas sesiones empezaron exactamente un año después, el 6-VII-1684.

${ }^{42}$ La gestión de la creación del colegio en Madrid la hizo la vasca Congregación de San Ignacio de Loyola, según consta en el impreso El Rey. Por quanto el Rector y Diputados de la Cofradía ..., s.e., s. 1., 1756, con las constituciones del colegio. Todo en ACSFN, caja 1 exp. 1-13.

43 Sus decisiones quedaron recogidas en los libros de acuerdos: Libro de acuerdos de la Real congregación del Glorioso San Fermín, patrón del Reyno de Navarra, ms., 573 folios, sesiones de 6-VII-1684 a 1-VII-1753, y Libro segundo de acuerdos de la Real y Primitiva Congregación del glorioso Statn Fermín, primer obispo y mártir español, ms., 589 folios, sesiones de 22-VII-1753 a 12-XII-1875, ambos en ACSFN s/sig. En adelante se cita como Libros de acuerdos, seguido de la fecha de la sesión y folios. La fecha identifica si la cita es del libro primero o del segundo. El primero lleva numeración a lápiz y sólo del folio recto, por tanto se cita por folio recto/verso; pero en el segundo los folios llevan numeración sucesiva, y así se cita. He consultado las actas desde la constitución hasta el acta de 30-V1814 , ff. 454-454v, la primera en que consta que la guerra y la ocupación francesa habían acabado. 
No sabemos qué fue en concreto lo que impulsó la creación de la congregación navarra en 1684, pero en cualquier caso hay un hecho que debió tener relación: apenas dos años después, en 1686, se creaba la primera asociación empresarial de gremios mayores de Madrid para tomar en arriendo los impuestos del rey en la capital. Los grupos de vascos y navarros probablemente ya entonces tenían una presencia fuerte en esta asociación gremial, que en pocas décadas se transformó en una auténtica corporación industrial, comercial y financiera que aún hoy sigue siendo apenas conocida. La corporación Cinco Gremios Mayores de Madrid fue clave para el desarrollo de la capital, que se convirtió en el principal centro mercantil y financiero de España. La posición de ambos grupos en la administración real era ya poderosa, y como en 1684 se fundó la congregación navarra y en 1715 la de los vascos, ambos hechos coincidían con el ascenso de la influencia de las colonias de navarros y vascos en el mundo administrativo y financiero madrileño. Los navarros no se juntaron sólo para reforzar sus relaciones mutuas o prestar asistencia social a los navarros pobres, sino también porque ello era la expresión social de un poder creciente.

Desde 1684 por lo menos una vez al año la congregación celebró una junta general en torno a la fiesta de San Fermín (7 de julio), a la que asistían todos los que podían, dedicada sobre todo al nombramiento y renovación de los oficios. Entre 1706 y 1724 hubo muy pocas juntas y la institución estuvo prácticamente paralizada, aunque sólo en 1706, año en que Madrid fue invadida por tropas inglesas y portuguesas a favor del archiduque Carlos, no se celebró san Fermín. En 1708-1709 y 1715 no hubo ninguna junta, apenas una entre 1716 y 1719 , y por esos años se constatan quejas de que no había renovación de cargos. Desde entonces hubo una junta general al año, una o dos juntas particulares y sólo en algunas ocasiones juntas de comisión para asuntos concretos. Las listas de asistentes sólo se consignaron bien desde comienzos del siglo XVIII. Pero a partir de aproximadamente 1724, coincidiendo con la estabilización política subsiguiente a la guerra y el decreto de 1721 citado transformando el régimen de naturalidad, el número y actividad de las sesiones creció notablemente. Desde los años 30 en adelante tendieron a aumentar, celebrándose más o menos una por mes.

La Congregación de San Fermín de los Navarros reunió en su seno uno de los grupos de poder más importante de la España del siglo XVIII. No obstante, lo que la institución pudo hacer por sí, con ser relevante, lo fue menos que lo que hicieron muchos de sus miembros, individualmente o en red. Aquí me centraré en la actividad institucional. Las fuentes dan información institucional fiable y casi no proporcionan información sobre los individuos congregantes, pero cuando lo hacen es de gran interés. En general las discusiones confraternales versaron sobre todo sobre temas puntuales: la admisión de congregantes, los nombramientos de oficios, y la actividad económica y benéfica.

Los asistentes a las juntas frecuentemente encontraron problemas para nombrar los numerosos cargos de la congregación, y recurrieron a individuos que no estaban presentes o no asistían a las sesiones. Los cargos se elegían por 
votación secreta, que en realidad casi era cooptación porque las juntas salientes proponían nombres según un cierto orden de rotación. Algunos cargos de especial responsabilidad: abogados, asistentes de pleitos o tesorero, de hecho se asignaron a ciertos individuos durante largos períodos de tiempo, aunque fueran confirmados por votación regularmente. El sistema de elección por votación fue regular desde la reorganización postbélica de las actividades, en la década de 1720, y parece que fue degenerando en la década de 1780, hecho que quizás tenga relación con cambios que por entonces se produjeron en la composición social de la congregación. No obstante para 1796 se había vuelto al sistema primitivo, año en que un congregante se quejaba de que

«...la elección debe hacerla la Junta General por medio de votos secretos como se hacía antes, no obstante que esta práctica quedó sin efecto desde el año de 1780; cuyo punto se redujo a votación y de ella resultó que en lo subcesivo se haga la elección de oficios por medio de votos secretos, distribuyéndose para el intento a los señores vocales concurrentes las cédulas impresas con los nombres de los propuestos...»44

lo que atestigua que los nombres a votar eran seleccionados previamente. En cuanto a la repetición de ciertos nombres para ciertos oficios,

«...convino la Junta en que todos los destinos que se hallan establecidos para su buena servidumbre son cargas con ninguna utilidad [= beneficio], y como adictas a los mismos individuos es muy debido circulen por todos, porque nadie se tiene por menos que otro; pero que sin embargo hay algunos destinos en la congregación que por su clase y naturaleza es conveniente subsistan radicados por algún tiempo en unos mismos sugetos, para que en él puedan adquirir toda aquella instrucción y conocimiento que se requiere y la Congregación debe apetecer para proceder con acierto en todas sus deliberaciones» ${ }^{45}$.

Los más implicados en el gobierno de la congregación fueron quienes asistían a las juntas y quienes ocuparon oficios, pero no siempre el tener cargos en ella significaba eso y sólo eso. Las redes familiares, los vínculos de patronazgo y clientela entre navarros y de éstos con otros grupos, en buena medida existían antes que la institución y discurrieron de modo independiente casi siempre. Ocupar un oficio podía ser un honor, o una oportunidad, pero podía tener además otro significado más importante como acción dentro de una estrategia familiar o de red, y de ello la fuente no da información alguna. Sí permite sin embargo abordar otro aspecto importante: quiénes fueron, en términos de nivel social y profesional, los que formaron esta asociación piadosa.

\footnotetext{
${ }_{44}$ ACSFN, Libros de Acuerdos, 29-VII-1796, ff. 390-393v, la cita en f. 391v-392.

45 ACSFN, Libros de Acuerdos, 29-VII-1796, ff. 390-393v, la cita en f. 392-392v.
} 


\section{LA COMPOSICIÓN SOCIAL}

El análisis de la composición social de la congregación determina de quiénes estamos hablando, sus intereses económicos y de poder, y al servicio de quiénes tuvo actividad la propia institución, y esto es posible saberlo porque podemos identificar sus miembros. Se conservan las altas de los congregantes (con exactitud sólo desde principios del siglo XVIII) y tres listas de congregantes: las de los que fundaron la congregación y dos que se hicieron para que los asistentes a las votaciones supieran quiénes eran elegibles. El análisis biográfico de cada individuo permite saber de quién se trata ${ }^{46}$.

Vayamos primero con las altas en la congregación. El total anual, que he contabilizado sólo para el período 1684-176047, muestra primero que entre 1686 y 1725 el número medio por año fue de 7,6 individuos. Puede que fueran más, porque hasta aproximadamente 1715 no todas quedaban registradas en las actas, que es lo único que nos queda. Entre 1725 y 1756 la media fue de 16,5 nuevos congregantes por año; considerando un ingreso hacia los 20 años y un promedio de vida de 35 años, puede deducirse que en el segundo cuarto de siglo la congregación aumentó notablemente sus miembros, alcanzando cifras en torno al medio millar de congregantes, lo que coincide con el hecho de que fue el período de más actividad de la institución.

Las listas proporcionan más información. La primera recoge los que participaron en la reunión promotora del convento de franciscanos mínimos de la Victoria, Madrid, el 25-IX-1683, en presencia de un escribano. Por tanto no es propiamente de congregantes, sino de navarros que al año siguiente se hicieron congregantes, probablemente todos. Tenían residencia en Madrid y «...dixeron ser naturales del Reyno de Navarra...» ${ }^{48}$. La condición de natural de Navarra y candidato a ingresar se mantenía hasta el cuarto grado de parentesco - como veremos más adelante-, de modo que muchos de la lista podían ser nacidos

46 Para hacerlo se han introducido los nombres de todos los congregantes en la base de datos FICHOZ (Fichier Ozanam), base de datos prosopográfica relacional sobre el Antiguo Régimen español, gestionada por Jean-Pierre Dedieu, Laboratoire de Recherches Historiques Rhône-Alpes (LARHRA) del Institut des Sciences de l'Homme, Lyon, edición de 11-X-2005. Esta labor implica una larga tarea de identificación de individuos en un fichero que contiene más de 250.000 registros sobre unas 100.000 personas.

47 ACSFN, Libro de asientos, sin título, $355+1 \mathrm{ff}$. manuscrito. Registra las altas de viceprefectos y congregantes entre 1684 y 1891.

${ }^{48}$ Fundación ... y constituciones de la Real Congregación Nacional de los hijos y descendientes del Nobilísimo y Fidelíssimo Reyno de Navarra que residen en esta imperial Villa y Corte de Madrid. Consagrada a San Fermín, primer español obispo, y primer Obispo en la anquisísima iglesia de Pamplona, como también primer mártir español. En reverencia y culto de su venerable reliquia y sagrada cabeza que está en el muy religioso Convento de la Victoria de Mínimos de San Francisco de Paula de esta Corte. Debaxo de la cathólica y augusta protección de nuestro Rey y Señor D. Carlos Segundo de este nombre, sin primero en el poder y piedad, s. 1., s. e., 1684. Reedición facsimilar, Real Congregación de San Fermín de los Navarros, Madrid 1989, p. 22. 
en y vecinos de Madrid sin perjuicio de pertenecer a la nación. La lista comprende 207 individuos varones, que no eran los que asistieron físicamente (algunos no pudieron ir) sino los que «...declararon en voz ser los que han fomentado y contribuido con sus diligencias...» a la constitución de la congregación. Todos en común eligieron, probablemente por aclamación, como miembros fundadores ${ }^{49}$ a ocho individuos que fueron los que actuaron en nombre de los demás. Estos ocho a su vez nombraron a siete poderhabientes, que fueron los que hicieron los trámites legales. La aprobación de la congregación se hizo el $16-\mathrm{V}-1684^{50}$ y fue entonces cuando propiamente empezó el registro de congregantes, que aumentó la cifra inicial: en 1684 y 1685 se inscribieron finalmente 253 individuos varones.

Hay dos listas más, que se hicieron para saber quiénes eran los congregantes en activo que podían votar y ser votados. La primera, manuscrita, declara llegar hasta el 16-VII-1731, pero el último nombre anotado es de 1742. Comprende hombres y mujeres ${ }^{51}$. La segunda es idéntica, se usó en asambleas (está impresa porque se hicieron copias), recoge altas (sólo hombres) desde 1705 y llega hasta el 12-IX-1755, con nombres añadidos a mano hasta $1763^{52}$. Ambas recogen los datos electorales relevantes: si los congregantes eran fundadores, si estaban en Madrid o no, si habían muerto, y su antigüedad, porque en caso de empate de votos prevalecía el congregante más antiguo. Ambas son incompletas, y en la segunda las mujeres ya no aparecen; no eran elegibles y no se vio necesario incluirlas 53 .

La lista de 1742 comprende los ingresados entre 1684 y 1742 que estaban vivos, los que para entonces habían muerto (pero no forzosamente todos), y mujeres monjas y viudas de congregantes. Son 378 individuos, de los que 127 $(33,6 \%)$ eran mujeres. En cuanto a la de 1763 , restando los ingresados hasta

49 «Y para que se ponga en execución, unánimes y conformes, eligen, para que por sí y en nombre de todos den poder a quien pareciere más conveniente para ello, ...»; Fundación... (1684), p. 27.

${ }^{50}$ Fundación... ob. cit.

${ }^{51}$ Relación de los congregantes de la Real Congregación del inclito patrón San Fermín, primer martir y obispo español, en la antiquísima iglesia de su patria, la muy noble y muy leal ciudad de Pamplona, por la anterioridad de sus asientos, ms., [1742], ACSFN, Congregantes, exp. 6-3. La lista de mujeres comprendía un cierto número de monjas que no podían figurar más que como tales: se consideraba que al adquirir tal condición «se casaban con Cristo». Del resto, un cierto número eran viudas de congregantes varones. No tengo medio de saber si además había mujeres navarras que ingresaron sin estar casadas. Nada prohibía el ingreso de mujeres, pero tengo la impresión de que ellas sólo entraron casadas o como monjas.

52 Relación... (1763).

${ }_{53}$ Los libros de asiento de socios se han perdido, tal como indica el encabezamiento del propio manuscrito. En las altas de 1736 a 1739 aparece el número del folio del libro de registro en que cada congregante quedaba asentado y la foliación de los asientos concide en varones y mujeres, lo que indica que había un solo libro de registro, «el libro de los asientos». Las anotaciones de folio consignadas en la lista impresa siguiente (1763) demuestran que el libro de asientos continuó. Las constituciones de 1684 habían ordenado crear un libro así; Fundación..., constitución VI, pp. 18r-19r. 
1742, comprende 237 individuos; monjas, mujeres y viudas pudieron sumar unos 300 congregantes más ${ }^{4}$. En total en 79 años (1684-1763) entraron al menos 489 hombres que pudieron ser con las mujeres unos 733 congregantes, lo que supone una media anual de 10-11 altas de hombres y mujeres, tanto individuos como matrimonios. La suma de las altas consignadas en las actas de las tres últimas décadas de este período daba una media superior, de unos 16,5 individuos al año. En resumen las cifras (253 varones en 1685, 251 en 1742, 237 en 1763, que con mujeres podían ser 400 ó 500) muestran que fue una congregación estable de las más grandes de Madrid.

Esta información permite abordar el objetivo de conocimiento que aquí pretendo: averiguar en un plano cuantitativo y no sólo cualitativo, cuál era la composición social de la congregación, y si experimentó alguna evolución a lo largo de la centuria. Las listas permiten saberlo para la primera mitad. Para hacerlo escogido el análisis biográfico individual de dos muestras de congregantes de la lista de 1742 . He tomado los 21 nombres más antiguos, que causaron alta entre 1684 y 1703 , es decir antes de la Guerra de Sucesión, y los 21 nombres más recientes, que causaron alta en los años 1741 y 1742 .

Es bien conocido por numerosos testimonios que la congregación estuvo compuesta desde el principio por nobles, altos funcionarios y mercaderes ligados con negocios al Estado. He intentado averiguar algo más sobre esto, y para ello he organizado los nombres en tres grupos que se corresponden con trayectorias biográficas diferenciadas por el tipo de conocimientos que se suponía tuvieron los que las ejercieron:

A- Individuos que pertenecieron a la alta nobleza o aparecen ocupando oficios más o menos relevantes en consejos, casa real, ejército y otros organismos, excluyendo aquellos que requerían contabilidad y cálculo económico.

B- Individuos que fueron asentistas o comerciantes, ocuparon oficios más o menos relevantes en organismos económicos y en cierto momento pudieron adquirir títulos de (generalmente) baja nobleza.

C- Individuos de los que hay datos de que iniciaron carrera eclesiástica y por tanto pertenecieron al clero, alto o bajo.

La información proporcionada por Fichoz permite esta tarea. Para la muestra de 1684-1703 de los 21 nombres considerados hay datos suficientes para definir el perfil profesional de 15 de ellos. De la muestra de 17411742, de los 21 congregantes considerados, he encontrado datos para 17.

Para los congregantes ingresados entre 1684 y 1703 el resultado es este: seis congregantes pertenecen al primer grupo $^{55}$, otros seis al segundo ${ }^{56}, \mathrm{y}$

${ }^{54} \mathrm{Si}$ añadimos una proporción equivalente de mujeres viudas y monjas, ya que no aparecen.

55 Antonio Álvarez Toledo Beaumont, duque de Alba (núm. 036200, que ni siquiera nació en 
tres al tercero ${ }^{57}$. Para los congregantes ingresados en 1741 y 1742 el resultado es este: ocho congregantes pertenecen al primer grupo $^{58}$, siete al segundo ${ }^{59}$, y dos al tercero ${ }^{60}$.

La muestra es pequeña, pero creo que marca una tendencia. Hasta 1703, poco antes de que empezara la Guerra de Sucesión, los navarros congregantes procedían de la administración, y casi la mitad estaban o acabaron estando ocupados

Navarra; consejero de Guerra y Estado, gentilhombre de cámara del rey); Melchor Fernández de la Cueva Enríquez, duque de Alburquerque (núm. 043329, capitán general del Mar Océano); Francisco Castejón (núm. 005735, oficial y luego secretario de varias secretarías del despacho y consejos); Vicente Pérez Araciel (núm. 005735, nacido en Alfaro, Rioja, consejero del Consejo de Castilla y consejero decano del de Órdenes Militares); Pablo Escalzo Acedo (entró en la congregación con 12 años, oficial de secretaría de los consejos de Estado y Guerra, protegido del castellano Manuel Vadillo Velasco) y Bonifacio Gaztelu Pereda (núm. 013201, viajó a Trujillo, Perú).

${ }^{56}$ Juan Goyeneche Gastón (núm. 015600, navarro del Baztán, felipista, tesorero mayor de la reina ya en 1701); Agustín Merizalde Funes (núm. 014737, oficial mayor y luego contador veedor de la contaduría de Obras Reales); Tomás Iriberri Goyeneche (núm. 006575, con el tiempo tesorero general de la de Rentas Generales y Agregadas y consejero de Hacienda); Francisco Javier Goyeneche Balanza (núm. 006575, marqués de Belzunce, tesorero y consejero del Consejo de Indias, tesorero y prefecto de la Congregación de San Fermín; creador de las fábricas de Nuevo Baztán, Madrid); Martín Ibero (núm. 001228, oficial de la Tesorería General), y José Ochoa Baquedano (núm. 044049, asentista de la provisión de pólvora en 1704-1714).

57 Simón Sanz (núm. 044036, presbítero en 1694); Agustín Castejón (núm. 044037, jesuita, catedrático en colegios de la Compañía de Jesús en Alcalá y Madrid) y José Folch (núm. 044048, presbítero en 1742).

${ }^{58}$ Francisco Bucareli Ursúa (núm. 000114, nacido en Sevilla, presidente de la Real Audiencia de Mallorca, gobernador y capital general de las provincias de Río de la Plata, virrey y capital general del reino de Navarra, presidente del Consejo de Navarra), Nicolás Bucareli Ursúa (núm. 000839, nacido en Sevilla, mariscal de campo, gobernador y corregidor de Cádiz, capitán general), Andrés Bereterechea (núm. 010070, cirujano de la Real Familia y del ejército), el marqués de Rivera (núm. 014550 — quizás es el marqués de Ribera de Tajuña-, mayordomo de semana del rey, caballerizo mayor de la princesa de Asturias), Andrés Díez Navarro (núm. 010622, nacido en Madrid, colegial mayor, fiscal del Concejo de la Mesta, de la sala de Alcaldes de Casa y Corte, del bureo [junta de gobierno de Casa Real] de la Casa de la Reina y del Consejo de Hacienda), Miguel Nava Carreño (núm. 000561, bautizo en Madrid, colegial mayor, alcalde de Casa y Corte, consejero de la Cámara de Castilla y gobernador del Consejo de Castilla), Pedro José Leoz (núm. 025221, secretario de la Inquisición en México) y Pedro José Zuera San Pedro (núm. 029266, ujier de cámara del rey).

59 Juan Francisco Ochoa Sarriés (núm. 023942, aprovisionador del ejército y contador de la Real Casa y Capilla), Juan Esteban Estenoz (núm. 021970, oficial mayor de la Pagaduría General de Juros), José Tomás López (núm. 001840, contador y fiscal de la Contaduría Mayor de Cuentas, autor de un tratado de contabilidad), Juan Garaicoechea (núm. 017362, veedor general de la Real Caballeriza del rey y secretario del rey), Pedro Iturriria (núm. 020821, arrendatario de las rentas provinciales de Guadalajara), Francisco Bartolomé Huarte Inda (núm. 020724, nacido en Madrid, asentista de presidios del norte de África, relacionado con el comerciante Juan Bautista Iturralde Gamio) y Miguel Arizcun Mendinueta (núm. 013491, marqués de Iturvieta, cuya compañía de comercio tomó en arriendo las rentas provinciales del reino de Galicia).

${ }^{60}$ Fray Juan Echeverría (núm. 044398, franciscano) y Gaspar Miranda Argaiz (núm. 016576, colegial mayor, obispo de Pamplona, asistente eclesiástico de las Cortes de Navarra). 
en oficios públicos que requerían conocimientos relacionados con el cálculo numérico. Se sabe que los navarros seguían una estrategia de educación específica en contabilidad y matemáticas; sin embargo es una condición necesaria pero no suficiente para explicar por qué ocupaban estos oficios. El factor determinante son las redes de casa y linaje en que cada uno crecía. No obstante, lo destacable no es eso, sino que los empresarios o asentistas declarados eran pocos.

A la altura de 1740 la proporción era la misma, pero los del grupo segundo implicados en operaciones mercantiles con el Estado eran o acabaron siendo cuatro individuos, dato que parece reflejar la importante promoción que se sabe tuvieron, de hecho, por su apoyo a Felipe V durante la Guerra de Sucesión. En las dos listas el número de clérigos es mínimo.

En resumen, a juzgar por estas muestras, la congregación nació como una asociación de altos funcionarios: la gran mayoría fueron ante todo servidores del rey en puestos la mayoría elevados y en cargos ejecutivos clave, como secretarías (oficiales, oficiales mayores, secretarios). Una elevada proporción de los congregantes (aproximadamente la mitad) ocuparon puestos relevantes relacionados con operaciones mercantiles dirigidas o provenientes del Estado, lo que confirma una estrategia deliberada de promoción en estos oficios que venía de atrás. Para entonces los navarros en conjunto ocupaban sobre todo ciertos sectores en la administración del rey: en especial órganos económicos como el Consejo de Hacienda, la Secretaría del Despacho de Hacienda, o la Junta General de Comercio y Moneda, donde la presencia de navarros congregantes era mayor. Como es lógico pensar, además muchos de ellos obtuvieron títulos nobles o la condición de caballeros de órdenes militares.

El análisis de la procedencia regional de los miembros de ciertos organismos económicos, como el Consejo de Hacienda, el tribunal de la Contaduría Mayor de Cuentas o la Junta General de Comercio y Moneda, perfila más el panorama. Para hacerlo he analizado las listas de quienes los componían, tomadas de la Guía de forasteros de $1742^{61}$. El Consejo de Hacienda tenía entonces 30 consejeros, divididos en tres salas: de Gobierno, de Justicia y de Millones. Tenemos información segura sobre la procedencia regional para 22; y de todos ellos sólo cuatro consta que con seguridad o alta probabilidad procedían de Navarra $^{62}$ o Provincias Vascongadas ${ }^{63}$ (aunque como se verá a continuación, no

${ }^{61}$ Recogidas en Francisco Olmos, José María de: Los miembros del Consejo de Hacienda y organismos económico-monetarios, Madrid, Castellum, 1997, pp. 44-45 y 273. Están publicadas también las listas de ingresados en el Consejo de Castilla para los dos períodos considerados, pero no tengo las de sus miembros en un año dado, que es algo bastante distinto, y no hay constancia de que los navarros o los vascos predominaran especialmente tampoco en este organismo; véase FAYARD, Janine: Los miembros del Consejo de Castilla (1621-1746), Madrid, Siglo XXI, 1982, pp. 242-249 y $508-514$.

62 Antonio Martín Vega Mauleón, marqués de Feria (Fichoz núm. 010767) había nacido en Olite, Navarra (1675-1757). De Bernardino Ezpeleta no tengo datos, pero los Ezpeleta eran navarros de Pamplona y en esos años dos con ese apellido eran congregantes de San Fermín de Madrid. 
era necesario nacer en Navarra para ser navarro). El tribunal de la Contaduría Mayor de Cuentas contaba ese año con 12 miembros. Tenemos información para 9; y de ellos sólo dos eran con seguridad o alta probabilidad navarros ${ }^{64}$, y ninguno vasco. En cuanto a la Junta General de Comercio y Moneda contaba con 11 miembros; tenemos información para 9, y de ellos sólo uno era navarro $^{65}$ o vasco. Hay una observación adicional de interés, uno de los navarros del Consejo de Hacienda: el consejero Antonio Martín Vega Mauleón, marqués de Feria, no era congregante de San Fermín, lo que confirma que no todos los navarros de la élite política estaban necesariamente en la congregación.

Lo que se acaba de decir muestra simplemente que los navarros compartían el gobierno y justicia en estos organismos con individuos de muchas otras pertenencias y adscripciones regionales y desde luego políticas, de procedencia mayoritariamente castellana. Las listas citadas comprenden 51 individuos, de los que sólo uno repite: pero no incluyen sin embargo, las de los oficiales, contadores y otros funcionarios de rango inferior, que eran más. No tenemos datos cuantitativos de su presencia a este nivel. Y en cualquier caso este análisis indica poco sobre la capacidad real de influencia de los que estaban, ni sobre sus conexiones, edad, experiencia de gobierno, capacidad de ocultación o manejo de información, dotes de liderazgo, o pertenencia a grupos de poder, factores que eran más importantes para medir el peso real de un grupo de poder en la administración que el mero número de miembros. Todo esto lleva a preguntarse quiénes podían formar parte de institución tan selecta.

\section{LA CUESTIÓN DE LA NATURALIDAD}

La respuesta a la pregunta es aparentemente simple: los que fueran navarros. Pero esto quiere decir que habían de poseer la naturalidad ${ }^{66}$ navarra, con-

Tomás Iriberri Goyeneche, marqués de Valbuena (Fichoz núm. 006575), había nacido en Maya, Navarra, y era congregante.

${ }^{63}$ De Martín Leceta (Fichoz núm. 005548) no hay datos sobre su origen, pero Leceta es localidad guipuzcoana. Es probable que él fuera de la provincia.

${ }^{64}$ Fermín Buenaventura Folch (Fichoz núm. 010849), el fiscal, era congregante desde 1710. De Manuel Sesma (Fichoz núm. 003230) no conocemos la procedencia, pero era accionista de la Real Compañía de La Habana, relacionada con los negocios de navarros; otro, Manuel Selma (probablemente Sesma) Monserrat (Fichoz núm. 003230) había sido contador en el tribunal, y otro probable pariente, Rafael Sesma (Fichoz núm. 005699), secretario del rey, contador de la citada contaduría, había sido congregante fundador de la de San Fermín.

${ }^{65}$ Casimiro Uztáriz Azuara, marqués de Uztáriz, congregante de San Fermín desde 1717 (1699-1751, Fichoz núm. 005340), nacido en Bruselas; era hijo de Jerónimo Uztáriz Hermiagua, nacido en Santesteban, Navarra (1670-1732, Fichoz núm. 006042), que había residido en Bruselas hasta el fin de la Guerra de Sucesión, fue congregante de San Fermín desde 1707 y vocal de la Junta antes que su hijo, a quien sin duda propuso para el puesto.

66 Sería erróneo identificarla con la actual nacionalidad. La naturalidad era un privilegio jurídico 
cepto en realidad nada banal porque tocaba la esencia misma de lo que era la comunidad política. El hecho de que distintos individuos eran naturales o tenían la naturalidad de territorios distintos dentro de la misma monarquía, fue uno de los factores que causaron la aparición misma de las congregaciones de nacionales, que por eso casi podrían ser llamadas también de naturales; de lo que los coetáneos llamaban también «cuerpos de nación».

La situación privilegiada de los navarros en la monarquía tiene su origen en un hecho único: los navarros, aunque siempre tuvieron sólo la naturalidad navarra, de hecho disfrutaron de una doble, navarra y castellana. En el Antiguo Régimen español la naturalidad fue un privilegio jurídico que ante todo generaba un derecho: obtener del rey cargos y oficios con que servirle y obtener rentas, incluidas las que se derivaban del Patronato Real del rey sobre cargos eclesiásticos. Así, las leyes que regulaban la naturalidad eran esenciales para conocer quiénes podían alcanzar el honor o la prebenda.

La íntima relación entre los hechos de ser natural de un territorio y tener derecho a ocupar cargos y oficios en él, especialmente eclesiásticos, es constante: la he comprobado en la legislación de Castilla, Navarra y Cataluña para los territorios respectivos, y muy probablemente se dio también en los demás reinos y territorios de la monarquía hispánica. En el caso de Castilla, el reino más importante, las leyes de naturalidad que definían quiénes eran naturales castellanos existieron desde fines del siglo XIV. Sin remontarse a antes, una disposición de 1585 determinó que lo eran los hijos de padre y madre (o en su defecto padre) naturales, con domicilio en ellos por al menos 10 años, y quienes nacían fuera de los reinos de padre o padres naturales, si eran hijos legítimos, o de madre natural castellana si lo eran espúreos (de padre desconocido) ${ }^{67}$. Es decir, la naturalidad se tenía por nacimiento, y el transmisor preferente era el padre.

En los siglos XVI y XVII el reparto y venta masivos de oficios por parte del rey provocó quejas de los estamentos del reino, que a través de las débiles Cortes castellanas intentaron controlar los procesos de naturalización, y mantuvieron una reserva de oficios ${ }^{68}$ que les siguiera dando un trato preeminente. Y como para ocupar cargos en Castilla había que ser castellano, hubo que definir, además de quiénes eran naturales, quiénes se hacían naturales: es decir, qué extranjeros podían obtener carta de naturaleza o naturalidad para ocupar cargos en los

político de alguien respecto a otros; sólo indirectamente definía su identidad en relación con los demás, que teniendo naturalidad distinta también podían ser súbditos del mismo rey. Ser natural era parecido a ser nacional o pertenecer a una nación en el sentido que entonces se daba al término, pero ambos no eran necesariamente equivalentes. En siglo XVIII empezaron a usarse con cierta ambivalencia, pero sólo tras la revolución burguesa la nacionalidad de un ciudadano acabó adscribiéndole a un Estado (nacional: así se le llamó en el siglo XIX) con los derechos y deberes que ello conllevaba.

${ }^{67}$ Nueva recopilación ..., lib. I, tít. III, ley XIX —I, p. 13- y NR, lib. I, tít. XIV, ley VII —I, p. 110 -

${ }^{68}$ Herzog, Tamar: Defining Nations. Inmigrants and citizens in Early Modern Spain and Spanish America, New Haven Conn, Yale University Press, 2003, pp. 76-93. 
territorios de la Corona de Castilla o en las Indias. En los procesos de naturalización fue competente el Consejo de Castilla hasta 1688, y desde entonces una sección especializada del mismo, en cierto modo otro consejo: la Cámara de Castilla o Consejo de la Cámara de Castilla, cuyo presidente lo era también del Consejo de Castilla ${ }^{69}$.

Con la supresión de los fueros y el Consejo de Aragón las naturalizaciones de Aragón, Cataluña y Valencia se transfirieron a la Cámara de Castilla. Poco después se crearon cuatro tipos de cartas de naturaleza para los extranjeros $(1716)^{70}$; los naturales de Castilla, Aragón, Cataluña y Valencia pasaron a poder obtener oficios y cargos eclesiásticos recíprocamente sin ser considerados extranjeros entre sí $(1723)^{71}$; y un tercer decreto suprimió de hecho la validación de las cartas de naturaleza por las cortes castellanas, que eran las únicas que quedaban (1721), mediante una filigrana jurídica ${ }^{72}$. Todo esto fusionó de hecho las distintas naturalidades de la monarquía española, debilitó definitivamente la reserva de oficios, abrió el abanico social de los que podían ocupar cargos y oficios, y — cómo no- reforzó el poder absoluto del monarca.

De todo esto quedó fuera el reino de Navarra, que constituyó un caso único en la monarquía hispánica porque siguió un proceso separado que tuvo origen en su confusa incorporación a la Corona de Castilla.

Cuando Fernando el Católico conquistó el reino en 1512 lo hizo con la intención de unirlo a sus otros reinos patrimoniales de la Corona de Aragón, y al modo de ellos: respetando leyes e instituciones. No hay duda sobre esto. Pero a principios de 1515, por razones políticas cambió de opinión, influido por el apoyo que el nuevo rey de Francia, Francisco I, daba al pretendiente al trono navarro, Juan de Albret. Castilla ofrecía más opciones para la defensa de Navarra frente a Francia, de modo que finalmente, como «administrador y gobernador» de Castilla, el 7-VII-1515, en Cortes de Castilla reunidas en Burgos en junio y julio de ese año, ratificó la incorporación de Navarra a la Corona de Castilla al modo castellano, es decir, de forma que el gobierno se haría desde las instituciones castellanas, aunque respetando los fueros navarros. Pero Fernando el Católico murió muy poco después, y su sucesor, Carlos I de Gante, no se atrevió a acabar el proceso de asimilación ${ }^{73}$.

El resultado fue que aquellos nobles navarros que habían apoyado a Fernando el Católico frente al rey francés, como premio empezaron a ser admitidos a los oficios de la monarquía castellana como si fueran castellanos, aunque

${ }^{69}$ Los procesos de Indias los resolvía el Consejo de Indias, y los de los reinos de la Corona de Aragón, el Consejo de Aragón, con decretos que luego el rey daba en cortes respectivas.

${ }^{70} \mathrm{NR}$, lib. I, tít. XIV, ley VI, nota 5 -I, p. 110-.

${ }^{71} \mathrm{NR}$, lib. I, tít. XIV, ley V -I, pp. 108-109-.

72 NR, lib. I, tít. XIV, ley VI, nota 4 -I, p. 110-.

${ }_{73} \mathrm{Me}$ atengo en lo esencial a la interpretación del proceso que ha dado Floristán Imízcoz, Alfredo: La monarquía española y el gobierno del reino de Navarra, Pamplona, Gobierno de Navarra, 1991, pp. 55-62. 
los fueros navarros subsistieron y las instituciones navarras no se suprimieron ni reformaron, permaneciendo intocadas.

El proceso de incorporación de Navarra a Castilla, jurídicamente tan poco claro, desencadenó desde el mismo siglo XVI una historiografía jurídico política interminable que aquí sólo cabe mencionar ${ }^{74}$. De ella por ahora interesa señalar sólo que se consolidaron dos ideas políticas. La primera es que la incorporación de Navarra a Castilla fue una unión principal o entre iguales («egüeprincipal»o equiprincipal), más parecida a las que se habían producido en los territorios de la Corona de Aragón, que mantenían fueros y órganos forales, que a las de la Corona de Castilla, donde los fueros y las instituciones castellanas generalmente pasaban a ser dominantes.

La segunda idea es que, a pesar de lo anterior, el privilegio de la naturalidad castellana que se concedía a los navarros como consecuencia lógica de su incorporación a la Corona de Castilla no desapareció. Los naturales navarros desde un principio fueron considerados castellanos y admitidos a cargos y oficios en Castilla. Estas dos ideas hay constancia de que fueron plenamente aceptadas por lo menos desde 1645, año en que el Colegio de la Santa Cruz de la Universidad de Valladolid se negó a admitir como colegial a un navarro por considerar que no tenía naturalidad castellana, las Cortes de Navarra elevaron una petición al rey contra ello y el rey accedió. La ley se incorporó a la recopilación foral ${ }^{75}$.

Así pues, por lo menos a mediados del siglo XVII estaba ya admitido que la unión había sido de dos reinos iguales, y que los navarros podían ocupar oficios en Castilla (y los castellanos en Navarra) indistintamente. Pero desde 1515 habían pasado 130 años y las cosas no podían ser tan simples. Durante ese tiempo los naturales castellanos difícilmente pudieron dejar de darse cuenta del doble privilegio de los navarros: políticamente seguían teniendo instituciones y leyes propias, y a la vez eran iguales a la hora de ocupar cargos y oficios en Castilla e Indias. Tenían las ventajas de la foralidad sin sus inconvenientes. Y el rey muy probablemente tampoco dejó de aprovecharse de estas ambigüedades a la hora de distribuir cargos y oficios reales y eclesiásticos a su conveniencia.

Estas dos ideas: que fue una unión entre reinos iguales y que los naturales navarros acabaron siendo aceptados a los oficios castellanos como los de Castilla, llevan a la cuestión central: cómo se conformó la naturalidad navarra, asunto que acabó centrado menos en la cuestión de quiénes eran naturales que en la de qué extranjeros se hacían naturales. Esto a su vez estaba relacionado con un

${ }^{74}$ La polémica puede verse en LEONÉ PUNCEL, Santiago: Los fueros de Navarra como lugar de la memoria, San Sebastián, Fundación para el Estudio del Derecho Histórico y Autonómico, 2005, pp. 63-87.

${ }^{75}$ Ley 6 de las cortes de Olite de 1645, en NRLN, lib. I, tít. VIII, ley XXXIII - I, pp. 404407- Poco después, en 1652, el rey volvió a darles la razón en un litigio parecido con el colegio mayor y universidad de Alcalá de Henares; ley 1 de las cortes de Pamplona de 1652 -ley XXIV; I, pp. 407-419-. El repertorio legislativo dedica un título entero a la naturalidad: NRLRN, lib. I tít. VIII leyes I-XXXIV — pp. 373-419-. 
hecho particular. La conquista de Navarra había sido parcial porque dejó fuera una parte del reino: la merindad de San Juan de Pie de Puerto (hoy Saint-JeanPied-de-Port), o de Ultrapuertos, o «Tierra de vascos» ${ }^{76}$, o Basse Navarre, que con los Albret fue reino independiente hasta 1589 (en que Enrique III de Navarra pasó a ser a la vez Enrique IV de Francia) y se fusionó con Francia en 1620. Muchos de estos navarros, que aquí por comodidad llamaremos navarros franceses, siguieron considerándose así y acogiéndose a sus fueros y naturalidad.

No sabemos hasta qué punto los navarros franceses siguieron siendo considerados navarros tras la incorporación de Navarra a Castilla. Probablemente su situación fue poco definida por un tiempo, como lo fue la conquista misma, que sólo el tiempo convirtió en definitiva. Sea como sea, lo cierto es que durante unas décadas, ellos siguieron atribuyéndose a sí mismos la naturalidad navarra, sinceramente o por interés. En fecha tan temprana como el 28-IX-1526, los habitantes de San Juan de Pie de Puerto, cabeza de la merindad de Ultrapuertos o «Tierra de vascos», ratificaban su fidelidad a Carlos I de Gante como rey de Navarra ${ }^{77}$. En 1580, en el marco de las guerras de religión que por entonces asolaban Francia, la cuestión de la naturalidad de los vecinos franceses pasó a primer plano: ese año el rey y las cortes de Pamplona aprobaron en su ley 40 que [Vuestra Majestad]

«...tiene declarado ser natural el que fuere procreado de padre o madre natural habitante en el dicho Reino de Navarra; y el que fuere nacido en el dicho Reino de extranjero no natural, y habitante, no se entienda ser natural del dicho Reino, ni pueda gozar de las libertades, y preeminencias, ni naturaleza. La cual solos los tres Estados, y no otro alguno, la dé y pueda dar»78.

Se confirmaron así dos importantes privilegios: que en adelante serían considerados naturales navarros sólo los nacidos de padres que residieran en el reino, y no quienes sólo cumplieran una de las dos condiciones, y que sólo «los tres brazos» reunidos en cortes eran quienes podían otorgar la naturalidad navarra. Esto otorgaba a la institución beneficiaria, las Cortes de Navarra, un importante instrumento jurídico cuyo uso con el tiempo tendría consecuencias sociales y políticas.

Tres años después, la definición de la naturalidad navarra quedó completada cuando las cortes de 1583 pidieron y el rey concedió que los «navarros franceses» $\mathrm{O}$ «vascos» no fueran considerados navarros:

${ }^{76}$ Término que aquí hay que leer no como «la tierra de los vascos» sino como «la tierra de los que hablan vasco». Al oeste de esta zona francesa estaba Labourd (Labort en castellano, Lapurdi en vasco), y al este el condado de Soule (Sola en castellano, Zuberoa en vasco) donde también se hablaba vasco. Además había muchos vascos y navarros que no eran vascoparlantes en el sur de los actuales País Vasco y Navarra españoles.

77 Yanguas Miranda, J.: Diccionario de antigüedades del Reino de Navarra, Pamplona, Diputación Foral de Navarra, 1964 (reedición), pp. 423-426; apud FlORISTÁN: ob. cit., pp. 83-84.

${ }^{78}$ NRLN, lib. I, tít. VIII, ley I - I, p. 373-374-. El libro y título se dedican a la naturalidad navarra y proporcionan más referencias al respecto. 
«Por leyes de este reino está ordenado y mandado que los estrangeros no sean admitidos en este reino en oficios y beneficios, y sin embargo de esto los [navarros] vascos han pretendido no ser estrangeros y que pueden tener oficios y beneficios en este reino. Y pues ellos son súbditos y vasallos de otro príncipe suplicamos a vuestra magestad ordene y mande interpretando las dichas leyes [...] que los [navarros] vascos se tengan por estrangeros y no se admitan en este reino en oficios ni beneficios, vicarías y pensiones [...] Y lo mismo se entienda y haga con los franceses $\gg 79$.

Esto privaba de la naturalidad navarra a los navarros franceses, que como consecuencia dirigieron al rey un memorial en 1586 en el que alegaban que hasta 1583 cuando iban a residir a la Navarra española habían venido siendo considerados navarros a todos los efectos:

«[... los naturales nacidos dentro de la villa de San Juan [de Pie de Puerto] y los otros lugares de la dicha merindad de Bascos que han pasado a vivir y residir de los puertos a esta parte [...], como naturales de él han gozado de lo que gozan los otros naturales de las otras cinco merindades de este reino, y han sido nombrados y admitidos en oficios reales de justicia y gobierno y beneficios eclesiásticos y curazgos como los otros naturales de este reino, sin distinción alguna y sin que haya sido necesario de naturalizarles como se requería si fueran extranjeros [...].

Se quejaban de la citada ley de 1583 , que había declarado extranjeros a «los naturales bascos» o navarros franceses y pedían que se revocara. Argumentaban que cuando en 1512 Fernando el Católico tomó posesión del reino, representantes de esta merindad también le habían jurado obediencia y fidelidad; que si desde 1527 las rentas de la merindad siguieron cobrándolas «los príncipes que han sido y son de Bearne» fue sólo porque el rey español les había dejado que la ocuparan; que cuando el príncipe de Bearn había defendido el luteranismo y castigado a sus habitantes católicos, éstos habían sido ayudados por los reyes, que les habían permitido pasar a la Navarra española a practicar su fe católica ${ }^{80}$; y que Carlos I y Felipe II habían recibido «a muchos caballeros y gentileshombres» de la merindad como súbditos suyos ${ }^{81}$. La emigración de católicos fue así un factor importante en la fijación jurídica de la naturalidad navarra. En cualquier caso en 1592 las cortes de Navarra ratificaron las leyes sobre naturalidad dadas en las de 1580 y $1583^{82}$, y desde entonces los navarros franceses, como extranjeros, quedaron obligados a solicitar la naturalidad a las Cortes de Navarra.

79 Ley 47 de las cortes de Tudela de 1583, NRLN, lib. I, tít. VIII, ley VII —I, pp. 377-378-.

${ }^{80}$ Es decir: a emigrar temporal o definitivamente, al menos en algunos casos. Se refiere al reinado de Juana III de Navarra (1555-1572), que introdujo el calvinismo en el reino (1561).

${ }^{81}$ El documento completo en FloristÁN IMÍzCOZ: ob. cit., pp. 145-146, quien a su vez lo toma de IDOATE, Florencio: Esfuerzo bélico de Navarra en el siglo XVI, Pamplona, Diputación Foral de Navarra, 1981, pp. 406-408.

${ }^{82}$ Ley 20 de las cortes de Estella de 1592; NRLN, lib. I, tít. VII, ley VI —I, p. 377—. 
De esta forma tan compleja, desde mediados del siglo XVII los navarros que habían emigrado a Madrid y a las Indias a servir al rey se encontraron en una situación particular y privilegiada. Navarra había conservado sus fueros e instituciones; las Cortes de Navarra se reunían cada tres años sin necesidad de que el rey las convocara y controlaban la concesión de las letras de naturalidad o cartas de naturalidad navarra. Los naturales del reino, que antes de la conquista habían desarrollado redes sociales que enlazaban los dos territorios, definitivamente eran considerados como los castellanos, y desde el siglo XVI habían seguido recibiendo emigrantes franceses católicos que si conseguían la naturalidad podían, en tanto que navarros, pasar a ocupar oficios y prebendas en Castilla.

Por eso cuando los emigrantes navarros en Madrid determinaron quiénes podían entrar en la congregación, sabían que regulaban lo que ya entonces se veía como un privilegio común a toda la diáspora: el de ser navarro.

Las constituciones de la congregación, en 1684, especificaron esto y algo más, al establecer que

«Los congregantes hayan de ser naturales o descendientes de aquel reino a lo menos por una de las dos líneas, paterna o materna, hasta el cuarto grado inclusive, y lo mismo se entenderá de los legítimamente naturalizados, [...] y se declaran por naturales todos los que teniendo su origen de aquel reino tienen y conservan en él por sí mismos casas ilustres o conocidas. Y gozarán también de la calidad de naturales los maridos de mujeres que lo son y las mujeres de maridos que así bien fueren naturales, en la forma dicha» 83

Es decir que para ser congregante era necesario ser navarro, pero el descendiente podía serlo por vía paterna y también materna, porque la mujer era transmisora de naturalidad. Por eso con toda probabilidad cada congregante casado que ingresaba incluía a su esposa, no tanto por ser mujer cuanto porque el matrimonio otorgaba naturalidad foral y por tanto en caso de fallecimiento del varón congregante la mujer pasaba a tener los derechos del marido, aunque luego nunca formó parte de las juntas ni ocupó oficios. En el libro de altas no firmó ninguna mujer, sin embargo se conserva alguna lista de mujeres congregantes. Sería un error pensar que las mujeres no tenían peso en la congregación: no sólo porque obviamente a través de las relaciones domésticas y personales podían influir en el marido y parientes, y mucho; sino también, y sobre todo, porque eran transmisoras de naturalidad. La adquirían si estaban casadas con un natural, la transmitían al marido si no lo era, y por supuesto la pasaban a los hijos.

${ }^{83}$ Fundación... (1684), constitución VI, pp. 18r-19r. Cada generación es un grado. El cuarto grado de parentesco significa que por línea recta o directa podían ser congregantes los tataranietos (hijo-padre-abuelo-bisabuelo-tatarabuelo) y por línea colateral los primos carnales (hijo-padreabuelo-tío-primo). 
Las constituciones de 1684 muestran también que no todos los naturales navarros podían entrar en la congregación, que admitía sólo a los que pertenecían a una casa abierta y activa. La razón está en que la naturalidad, de acuerdo con las leyes forales expresadas, exigía residencia física. La emigración navarra hacia el sur, incluido Madrid, había provenido sobre todo de los valles del norte de Navarra, y allí permanecía vigente un régimen civil de transmisión patrimonial basado en el heredero único y la casa: el heredero recibía todo el patrimonio, y los demás descendientes habían de emigrar ${ }^{84}$. Esto y la presión demográfica había llevado a la prohibición de erigir más casas y a que los restantes descendientes fueran objeto de estrategias educativas orientadas a que pudieran ganarse la vida con un oficio: por ejemplo la milicia, la religión o el comercio. Los descendientes para mantener la naturalidad no podían perder contacto: iban a nacer allí, aprendían vasco, eran educados y protegidos por padres y parientes, y luego hacían lo mismo que los demás: cada emigrado seguía perteneciendo a una casa, y el éxito individual había acabado siendo el de ésta, además de sinónimo ideal de nobleza. Uno de los fundadores de la congregación, Juan de Goyeneche, lo expresaba perfectamente en 1685 , refiriéndose a su valle:

«...está todo el territorio [del valle de Baztán] dividido con tal proporción entre los vecinos que a cada casa le corresponde la hacienda que parece competente para su conservación. Más porque multiplicándose las casas y excediendo el número de habitadores a los frutos que pueden tributar aquellos campos sería forzoso que el pueblo se redujere a la aplicación de los oficios mecánicos, que desdicen del genio de la nación y de los altos espíritus con que todos se crían y se conservan, hay ley, que inviolablemente se guarda, de que no se pueden hacer casas de nuevo, de suerte que multipliquen la vecindad y puedan perturbar el buen orden que para su conservación y su lustre dispusieron y observaron los antiguos. Lícito es a cualquiera de los vecinos el levantar su casa hasta las nubes, extenderla, fortalecerla y hermosearla según su gusto y su posibilidad, como también el fabricar caseríos para más comodidad de las haciendas; pero no es lícito fabricar habitación que aumente la vecindad, porque no se incurra en el deslucimiento y cortedad que suele ocasionar la muchedumbre $[\ldots]$ no todos nacen con medios para ostentar el lustre de su nobleza, y assí es forzoso que muchos lo adquieran con la industria, reduciéndose a discurrir por tierras extrañas para probar fortuna» 85

Hubo también algunos privilegios particulares. Las constituciones de 1684 establecieron además que podrían entrar los descendientes de los congregantes fundadores (entendiendo por tales los que se inscribieron en el libro de asientos

${ }^{84}$ Que no era exclusivo de Navarra, ya que estaba extendido también por lo menos por las provincias vascas, el norte de Aragón y el norte de Cataluña.

${ }^{85}$ Executoria de la nobleza, antigüedad y blasones del valle del Baztán, que dedica a sus hijos y originarios Juan de Goyeneche, Madrid, s. e., 1685, apartados II y IV, apud CARO BAROJA, Julio: La hora navarra del siglo XVIII (personas, familias, negocios e ideas), Pamplona, Diputación Foral de Navarra e Institución «Príncipe de Viana», 1969, pp. 23-24. 
hasta pasado un mes del comienzo de las actividades, poco después de la aprobación de las constituciones el 16-V-1684) hasta el cuarto grado de parentesco, y quienes no fueran naturales pero sí devotos de San Fermín, en especial si eran del obispado de Pamplona, en este caso previa aprobación de dos tercios de votos de la asamblea ${ }^{86}$.

Los navarros, que emigraron a Madrid desde el siglo XVI acabaron ocupando posiciones importantes en la administración de la monarquía, y las utilizaron a su favor para seguir colocando naturales o nacionales. En la segunda mitad del siglo XVII debieron tener ya bastante actividad mercantil privada en Madrid (por ejemplo en los gremios mayores), aunque su posición en los asientos de la monarquía española y su financiación todavía era pequeña ${ }^{87}$; pero con su apoyo al Felipe V en la Guerra de Sucesión la mejoraron mucho. Muchos eran congregantes, como ya se ha visto. También crecieron en influencia y número las redes de franceses, y es obvio que la relación privilegiada que los navarros tenían desde hacía más de un siglo con los primero navarrros franceses y luego - tras la unión de la merindad de San Juan de Pie de Puerto a Franciafranceses navarros tuvo que ver con ello, por fuerza.

Otras redes, de nacionales o no, intentaron desplazarlos, en un juego de escaramuzas del que la producción historiográfica sobre la administración de los Borbones ofrece numerosos casos concretos. Y las listas de los que habían ingresado en la congregación muestra que en ella hubo nobles cuyo título de origen era castellano, no navarro, lo que puede indicar que en algún momento habían adquirido la naturalidad a partir de una estrategia que les había llevado a adquirir posesiones y títulos en Navarra con la intención de conseguir la naturalidad foral, o a casarse con alguien que la tuviera. Si los naturales navarros ocupaban tantos cargos al servicio del rey, si eran un poderoso grupo de poder, tan práctico como desplazarlos era convertirse en uno de ellos. Y el matrimonio otorgaba naturalidad al cónyuge y grandes oportunidades de progreso, tantas cuantas tuviera a su alcance la casa de la novia. El microanálisis ofrece grandes posibilidades de averiguar por qué las redes de nacionales o naturales navarros tuvieron estímulos para crecer y otras no lo tuvieron, pero los límites de este trabajo obligan a dejar cuestión tan apasionante para volver nuevamente a lo general, la congregación de san Fermín.

${ }^{86}$ Fundación... (1684), constituciones VI y VII, pp. 18r-19v.

${ }^{87} \mathrm{La}$ mayor parte de los mercaderes banqueros en Madrid en esos 50 años fueron sobre todo italianos y portugueses, y de los 66 grupos que realizaron asientos para la monarquía sólo unos pocos fueron de origen vasco y navarro, como muestra SANZ AYÁn, Carmen: Los banqueros de Carlos II, Valladolid, Universidad de Valladolid, 1989, pp. 377-433. 


\section{LA ECONOMÍA CONFRATERNAL Y LA CONSTRUCCIÓN DE LA IGLESIA}

Corresponde ahora analizar la actividad económica, cuya empresa más importante en este sentido fue la construcción de una iglesia propia. Hubo varias vías de recaudación de dinero. Al ingresar cada aspirante daba una limosna, y estas entradas fueron las únicas fijas con que la organización contó regularmente, de tal modo que en ciertos momentos la admisión de nuevos congregantes pudo fomentarse simplemente porque daba ingresos. La carencia de fondos, sin embargo, fue problema sólo relativo para una organización muchos de cuyos miembros eran sobradamente más ricos que ella misma.

Una segunda vía de financiación, interesante y no conocida, era que algunos congregantes alguna vez le cedieron el cobro de deudas y créditos impagados; ésta se encargaba de hacerlo y se quedaba el dinero, si lo conseguía. La tercera no podía ser más aleatoria: había «cajas» o cepillos que los congregantes llevaban por las casas de los miembros para recabar limosnas. Una cuarta vía, extraordinaria, era pedir dinero a los congregantes americanos, lo que exigía el permiso del rey, que ostentaba el patronato universal en el Imperio americano. Hay que suponer que fue menos difícil obtener el permiso que el dinero.

La información disponible sobre todo esto es fragmentaria. En 1696 llegaron unos 2.000 pesos de limosnas recogidas por los emigrantes navarros en América ${ }^{88}$, y en 1727 la congregación nombró numerosos apoderados en las colonias para cobrar nuevamente limosna autorizada por el rey por cuatro años a sus demás paisanos dispersos por el imperio colonial ${ }^{89}$, un nuevo contacto con los emigrados que debió volver a sanear la caja. Las actas del siglo XVIII registran además algún ingreso extraordinario de capitales, bienes (especialmente joyas y objetos de culto) o rentas que los congregantes donaban al morir.

Pasada la Guerra de Sucesión, desde los años 30 las actas muestran que la congregación había establecido nuevamente y mantuvo contactos regulares con la diáspora navarra en las colonias, lo que le supuso ingresos muy variables pero frecuentes en forma de limosnas ${ }^{90}$. En parte esto es lo que le permitió acometer la obra de la iglesia y una activa labor de protección de los navarros en Madrid.

88 ACSFN, Libros de Acuerdos, 27-VII-1698, ff. 161-v-165r.

89 ACSFN, Libros de Acuerdos, 30-III-1727, ff. 272r-275r.

${ }^{90}$ La diáspora de navarros y vascos en América había sido intensa en los siglos XVI y XVII y aumentó en el siglo XVIII, si atendemos al caso de Buenos Aires (unos 4.000 habitantes en 1738; unos 42.000 en 1810), a donde entre 1580 y 1713 emigraron un centenar y medio de vascos y navarros (de ellos unos 60 fueron navarros). Entre 1713 y 1810 hubo al menos un centenar de navarros documentados: aproximadamente el $75 \%$ fueron comerciantes, el otro $25 \%$ funcionarios (quizás falten aquí navarros pobres porque éstos no solían dejar rastro documental). Los datos en Frías, Susana R., y García Belsunce, César A.: De Navarra a Buenos Aires, Buenos Aires, Instituto Americano de Estudios Vascos, 1996, pp. 19-66. 
A lo largo del siglo XVIII la congregación manejó unas previsiones presupuestarias anuales de ingresos y gastos de entre 5.000/10.000 a 50.000 reales de vellón, con frecuencia más cercanas a la parte baja de la banda que a la alta. En general en la segunda mitad de siglo las finanzas de la congregación estuvieron en déficit permanente: debía dinero siempre y dependía de las limosnas de los congregantes y las que daban los nuevos al causar alta. Fue costumbre que en los días de la festividad de San Fermín los asistentes, en mesa puesta en la sala de juntas, pagaran una limosna anual. Tal y como se detalla a continuación, la construcción de una iglesia nueva generó una deuda permanente. En los 70 por ejemplo ascendía a unos 100.000 reales de vellón, parte de la cual había sido originada por su construcción, y en 1799 aún se debían casi 27.000 reales de vellón por la compra del solar, hecha en 1744. No se conserva la contabilidad de la institución, y si nos atenemos a lo que aparece en las actas sólo de vez en cuando se pagaban pequeñas cantidades a acreedores, pero como éstos eran principalmente congregantes hay que suponer que o no las cobraron o que quizás lo hicieron por vías que no conocemos. Una forma de hacerlo era conseguir, a través de las redes familiares y clientelares, oficios cuyo desempeño otorgaba poder e ingresos económicos.

Pero en los años 30 la corporación estaba en su mejor momento, había altas y los congregantes participaban en las juntas, lo que les llevó a acometer la construcción de una iglesia y sitio propios, asunto cuya comprensión adecuada exige volver a situarse en la lógica de lo que en origen era una asociación piadosa para fomentar el culto a San Fermín en Madrid y practicar la caridad con sus «connaturales de patria» ${ }^{91}$.

La reunión fundacional se celebró en la sacristía del convento de franciscanos mínimos de San Francisco de Paula, llamado de la Victoria, de Madrid, en 1683, e inicialmente la sede de la institución estuvo allí. Pero pronto el convenio provocó grandes discusiones entre la congregación y los frailes en tres cuestiones. La congregación había de mantener en su poder la reliquia de San Fermín que tenía ofrecida el obispo de Pamplona, que no era del convento; había de poder nombrar a quien había de celebrar la misa y sermón de San Fermín, y había de poder quedarse con los exvotos, alhajas y regalos que dieran los fieles a la cabeza San Fermín o a la congregación. No debió haber arreglo estable, porque al poco, en 1685, la congregación estaba negociando otro posible convenio con tres conventos madrileños: el de la Trinidad, el del Espíritu Santo y el de la Compañía de Jesús92, y el 3-VII-1685 ya se trasladó al convento de la

\footnotetext{
${ }_{91}$ Tal como se declara en el preámbulo de sus estatutos: Fundación ... (1684), pp. 3r-4v.

92 Fundada por Ignacio de Loyola. Uno de los seis primeros miembros de la Compañía fue el navarro san Francisco Javier, como es sabido. Entonces en este convento estaba la congregación de San Ignacio de Loyola, la de los vascos; en la de San Fermín alguien debió observar (no inocentemente) que no se había tenido en cuenta que era «de vecinos» y — quizás por eso— se decidió elegir otro convento; ACSFN, Libros de Acuerdos, 25-II-1685, f. 28v. Desde 1685 la congregación celebró, además de la festividad de su patrón san Fermín el 7 de julio, la de san Francisco Javier que era el 3
} 
Santísima Trinidad ${ }^{93}$. La reliquia más preciada de la congregación, parte de la cabeza de San Fermín, donada por la catedral de Pamplona, llegó en 1686.

La pregunta de dónde la congregación iba a desarrollar el culto a San Fermín puede parecer hoy un asunto secundario, pero entonces no lo era en absoluto, tanto por razones de pura devoción para sus miembros como de economía eclesial para los que la albergaban. Las cofradías, congregaciones y otras asociaciones pías estaban adscritas a una parroquia, y el obispo y el párroco tenían competencias sobre ellas. Pero cuando la congregación tenía como residencia un convento también tenían competencias los priores o abades, lo que tenía consecuencias pastorales y económicas para los propios conventos, y suscitaba conflictos intraclericales entre parroquias y conventos, entre el clero secular y el regular. Los conventos de Madrid rivalizaban por conseguir la asistencia espiritual de nobles, fieles, mercaderes y funcionarios que cuando morían podían dejar en herencia al clérigo o la institución patronatos, capellanías, fundaciones o riquezas ${ }^{94}$. Por eso el lugar que eligiera como sede una congregación que reunía lo más granado de la élite funcionarial y mercantil de Madrid era algo que no dejaba indiferente a nadie. Es en este contexto donde hay que situar disputas clericales que en realidad no eran nada banales: tenían consecuencias importantes, no sólo litúrgicas sino también - y yo diría que sobre todo- de poder, influencia y rentas.

No hay más noticias sobre la ubicación hasta que, tras la guerra, la congregación cobró nuevo impulso. En 1731 los navarros se enteraron de que en el convento de la Trinidad, donde la congregación ocupaba una capilla lateral, los frailes, en secreto, planeaban colocar al venerable Rojas, un miembro de la orden que iba a ser beatificado próximamente, en sustitución del busto y reliquia de San Fermín, lo que les movió a empezar a buscar iglesia propia, también secretamente, con la idea de construir un hospital anejo ${ }^{95}$.

Sin embargo las gestiones para la compra de otro edificio no se iniciaron hasta 1743; un año después, en 1744, la congregación compró una parcela y edificio, la llamada casa («torre» con jardín) de Monterrey, parroquia de San Sebastián, que era propiedad de los herederos del conde de Monterrey, entonces habitada por un inquilino, el marqués de Villora. La casa y predio valían unos 330.000 reales de vellón, y la compra se abordó inicialmente con 39.300 reales de vellón de limosnas aportados por 46 socios más los acuerdos de pedir también donativos a todos los demás, incluidos los ausentes de Madrid, y que si

\footnotetext{
de diciembre (ACSFN, Libros de Acuerdos, 4-XI-1685, f. 47r), la de San Fermín parece que dejó de celebrarse por falta de fondos en 1704 y 1720 (ACSFN, ídem, nota manuscrita en f. 138r).

93 ACSFN, Libros de Acuerdos, 3-VI-1685, f. 32r.

${ }^{94}$ López García, José Miguel (dir.): El impacto de la Corte en Castilla. Madrid y su territorio en la época moderna, Madrid, Siglo XXI, 1998, pp. 215-229.

95 ACSFN, Libros de Acuerdos, 8-VII-1731, ff. 321r-324r, y 1-IX-1743, ff. 445r-447v.
} 
faltaba dinero se pidiera a censo contra la propiedad a adquirir ${ }^{96}$. Esto era una ingenuidad porque como los congregantes sabían bien el interés de los censos estaba muy bajo ${ }^{97}$; efectivamente se buscó dinero así pero no se encontró, por lo que al final la compra hubo de hacerse mediante un crédito de 1.000 doblones que pidieron «a su crédito» cuatro congregantes muy ricos en negocios con el Estado: el marqués de Iturbieta ${ }^{98}$, su entonces administrador, Ambrosio Agustín Garro ${ }^{99}$; el conocido Francisco Miguel Goyeneche, conde de Saceda ${ }^{100}$, y Pedro de Iturriria ${ }^{101}$. La congregación, y con ella los demás congregantes, quedó como responsable de devolver el crédito a los congregantes prestamistas. El dinero recaudado en efectivo quedó para empezar la edificación prevista más un edificio anejo a la iglesia con dos viviendas que se darían en alquiler. Las viviendas se calculaba que darían unos ingresos anuales de 7.000-8.000 reales de vellón al año, que permitirían pagar las obras en parte ${ }^{102}$.

Este dinero no fue suficiente. En 1745 los congregantes marqués de Iturbieta, el conde de Saceda, Pedro de Astriarena, Ambrosio Agustín Garro y Juan Antonio de Aldecoa prestaron otros 60.000 reales a la congregación para suplir las limosnas, insuficientes ${ }^{103}$, y poco después el conde de Saceda cedió a la congregación a perpetuidad

«una hazienda que le pertenece y se compone de unas casas principales de fábrica nueva y oficinas correspondientes, varias tierras de pan llevar, viñas, olivos, censos perpetuos y al redimir y un mesón en la villa del Pozuelo»

entonces llamada Pozuelo del Rey, que rentaban aproximadamente 50.00060.000 reales, con la condición de que una tercera parte de la renta se diera a otras dos obras pías: la congregación de Nuestra Señora del Pilar, de aragoneses, y los escolapios en Madrid, para un nuevo colegio ${ }^{104}$. La gestión de la hacienda no fue buena, la casa estuvo muchos años sin darse en arriendo y fi-

${ }^{96}$ Esto era muy difícil, un testimonio en ACSFN, Libros de Acuerdos, junta de 11-VII-1745, ff. $464 \mathrm{r}$ bis-468v. Por eso la financiación hubo de hacerse con créditos y donaciones.

${ }_{97}$ ACSFN, Libros de Acuerdos, 14-VII-1743, ff. 441r-445r.

98 Miguel Arizcun Mendinueta, que entonces era un importante arrendador de rentas provinciales en Castilla y luego fue nada menos que pagador de la superintendencia de juros, lo que le permitía conocer el estado de la deuda en toda la monarquía; Fichoz núm. 13491.

${ }_{99}$ Tesorero del infante don Luis y administrador de la casa del marqués de Iturvieta o Iturbieta; Fichoz núm. 001841.

${ }^{100}$ Entonces tesorero de la reina; Fichoz núm. 014873.

${ }^{101}$ Por entonces otro importante arrendador de rentas provinciales; Fichoz núms. 020821, 018734 y 008717.

102 ACSFN, Libros de Acuerdos, 10-V-1744, ff. 448r-452v.

103 ACSFN, Libros de Acuerdos, 21-III-1745, ff. 458v-459v.

104 ACSFN, Libros de Acuerdos, 19-IV-1745, ff. 461v-464v. La donación se hizo por escritura ante Juan Antonio de la Puente, notario de número, el 16-V-1746. ACSFN, Libros de Acuerdos, 16VII-1758, ff. 83-92, el dato en f. 86. 
nalmente se vendió en 1781 por sólo 5.500 reales de vellón ${ }^{105}$. En 1769 se liquidó un censo de 7.865 reales 19 maravedís procedente de la herencia y se acordó vender la casa de la hacienda, que entonces estaba dada en alquiler por poco dinero ${ }^{106}$. El importe del censo se volvió a imponer, al 2,5\%, sobre una deuda de 31.200 reales de vellón procedente de un crédito que tenía un vecino de Madrid, don Leandro Fernández de Ibarra, «con hipoteca especial» ${ }^{107}$, de tal modo que quedaba hipotecado al pago del rédito del censo ${ }^{108}$. El vecino lo redimió unos meses después. Parte del dinero se impuso también al 2,5\% sobre la Compañía de Caracas a la espera de poder comprar alguna acción suya ${ }^{109}$.

Nuevamente en 1746 el prefecto Francisco Mendinueta ${ }^{110}$, el conde de Saceda y otro congregante dedicado a negocios, Fermín Vicuña, dieron un préstamo de 21.000 reales de vellón a la congregación para pagar a Pablo de Torres, que había ejecutado planos y obras de julio de 1744 a enero de $1746^{111}$. La iglesia se acabó finalmente en mayo de ese año y poco después, el sábado 27-IX-1746, la imagen de San Fermín se trasladó en procesión solemne. El coste del traslado, la procesión y tres días de fiesta fue de casi 19.000 reales de vellón, que se pagaron con una limosna repartida a escote entre todos los congregantes $^{112}$. La iglesia recibió de inmediato donaciones de una docena de congregantes con objetos diversos para vestirla ${ }^{113}$, y otros más fueron enriqueciéndola con ornamentos litúrgicos y alhajas en años posteriores.

En 1747 la casa de la congregación adjunta a la iglesia se dio en alquiler al aragonés marqués de Cañizar y conde de Luna por 9.000 reales de vellón al año, pagaderos por semestres adelantados según estilo de corte ${ }^{114}$.

En 1749 la congregación estaba en un estado financiero muy malo porque tenía más de 500.000 reales de vellón en deudas sin pagar. Entonces la junta general, en sesión un tanto turbulenta y con los principales congregantes prestamistas bastante enfadados porque no se les restituían los créditos, a presión de éstos, acordó vender parte del solar adquirido a los herederos del difunto conde de Monterrey: la casa y huerta adjunta a la iglesia, donde pensaba construir un hospital para los navarros pobres. La idea era pagar parte de la deuda y

105 ACSFN, Libros de Acuerdos, 22-VII-1781, ff. 300v-303v.

106 ACSFN, Libros de Acuerdos, 30-VII-1769, ff. 221-222.

107 En lo que parecía un favor. Imponer un censo sobre un crédito es una operación a primera vista extraña y además el dinero puesto en el mercado podía dar más interés fácilmente.

${ }^{108}$ La escritura de censo se firmó el 23-X-1770 ante el escribano de Madrid Antonio Carraco y quedó registrada en la Contaduría General de Hipotecas. La gestión la hizo el tesorero de la congregación, Juan Luis de Iribarren. Todo en ACSFN, Libros de Acuerdos, 21-VII-1771, ff. 228v-230v.

109 ACSFN, Libros de Acuerdos, 13-X-1771, ff. 231v-233.

110 Otro individuo muy rico, entonces arrendador de rentas provinciales y asentista del ejército; Fichoz núm. 020752.

111 ACSFN, Libros de Acuerdos, 30-V-1746, ff. 469r bis-474r.

112 ACSFN, Libros de Acuerdos, 30-X-1746, ff. 490r-495r.

113 ACSFN, Libros de Acuerdos, 30-V-1746, ff. 469r bis-474r.

114 ACSFN, Libros de Acuerdos, 28-V-1747, ff. 497v-498v. 
acabar de saldarla con un censo (a interés bajo, claro) sobre la iglesia y edificio construidos. Para ello acordó comisionar a tres individuos: el conde de Saceda, Miguel Gastón de Iriarte $^{115}$ y Francisco de Mendívil ${ }^{116}$. Poco después, ya en 1750 , buena parte de la deuda de la congregación se liquidó finalmente, vendiendo parte del solar de la congregación al conde de Atarés por 179.000 reales de vellón y aceptando el traspaso de un censo de la marquesa de Ugena de 73.050 reales de vellón al 3\% a cargo de cuyos intereses sus herederos pagaban al capellán. Con el total se pagó buena parte de la deuda, que en ese momento era de casi 452.000 reales de vellón, a los cinco congregantes acreedores ${ }^{117}$. Una parte del dinero de la operación de la iglesia nunca llegó a pagarse: en 1755 la congregación seguía debiendo unos 141.000 reales de vellón a 13 congregantes que habían puesto dinero, y manejaba un presupuesto anual de gastos de sólo unos 9.000 reales de vellón ${ }^{118}$, y en 1799 la congregación seguía debiendo 26.714 rs. 27 maravedís "por resto de las cantidades invertidas en la compra del terreno que ocupa la Iglesia» ${ }^{119}$.

En 1769 el conde de Aranda, entonces presidente del Consejo de Castilla, intentó mover la iglesia del Paseo del Prado para dejar en el área sólo edificios ministeriales. Ofreció a la congregación permutar su iglesia por otra, la «de San Jorge y Escoceses», de los jesuitas expulsados, pero los navarros pidieron que en todo caso se les diera primero el de los padres llamados del Salvador (cuyo patrono era el arzobispo de Toledo) (puede que fuera la llamada «Iglesia de los Irlandeses», también de los jesuitas), y en segundo lugar el de los frailes de San Felipe Neri, ambos desocupados, y sólo en tercer lugar la primero citada ${ }^{120}$. Pero el arzobispo de Toledo tenía otros planes para la iglesia de San Jorge, y la edificación de la de los Irlandeses estaba muy mal para ellos. Al diputado de la congregación para el asunto, Joaquín de Olloqui,

«...el Sr. Fiscal [del Consejo y la Cámara de Castilla, Pedro Rodríguez Campomanes] en confianza le había manifestado últimamente hallarse en sus manos con el expediente sobre reunión de los Hospitales particulares al General, [y] que si tenía efecto quedaría tal vez arbitrio para aplicar a la Congregación Iglesia proporcionada ...»121

115 De la destacada casa baztanesa de los Gastón de Iriarte, entonces un importante militar naval; Fichoz núm. 10984.

116 ACSFN, Libros de Acuerdos, 28-XII-1749, ff. 532v-535r. Otra persona muy influyente: Francisco Fernández Mendívil Alcedo, congregante desde 1730, abogado y entonces fiscal de rentas generales en el tribunal de la Superintendencia General de Rentas; Fichoz núm. 002605.

117 ACSFN, Libros de Acuerdos, 28-X-1750, ff. 543v-547v.

118 ACSFN, Libros de Acuerdos, 31-VIII-1755, ff. 36-49, los datos en ff. 37-38.

119 ACSFN, Libros de Acuerdos, 30-VII-1799, ff. 408-412v, el texto en f. 410v.

120 ACSFN, Libros de Acuerdos, alusiones en sesión de 28-III-1769, ff. 216-218, y las siguientes, p. ej. 7-V-1769, ff. 218-220.

121 ACSFN, Libros de Acuerdos, 24-IX-1769, ff. 223-224v, la cita en f. 223v. Parece referirse a que por entonces el Consejo de Castilla estaba operando con los conventos desamortizados de la 
El intento parece que se dejó en 1770 , y volvió en 1772, pero finalmente no prosperó ${ }^{122}$. En agosto de ese año la congregación recibió una oferta del conde de Atarés, que hacía un tiempo había comprado la parcela contigua a la de la iglesia y allí residía, para comprar todo el sitio congregacional ${ }^{123}$.

Hechos así, aparentemente anodinos, adquieren significado propio cuando el análisis prosopográfico muestra que sus protagonistas mantenían complejas e intensas relaciones familiares, clientelares o de poder: redes que a veces colaboraban y a veces competían entre sí. En el caso que nos ocupa creo que estamos ante una estrategia inmobiliaria que venía de atrás y se desarrollaba en otra red social madrileña, la de los aragoneses, que para entonces habían creado un grupo de influencia en la Corte nucleado en torno al conde de Aranda. En 1747 el aragonés marqués de Cañizar había tomado en alquiler la casa adjunta a la iglesia, y en 1772, gracias a información probablemente filtrada, el conde de Atarés, que era también aragonés y con toda probabilidad familiar del conde de Aranda, ofrecía comprar la iglesia y el sitio enteros ${ }^{124}$. En este caso esta red aragonesa, cuya historia política fue hecha hace años por Olaechea ${ }^{125}$, aparece compitiendo con los navarros por ocupar un buen puesto en el escaparate urbano de la Corte.

\section{LOS NAVARROS Y LAS DEMÁS CONGREGACIONES. LOS VASCOS}

El análisis de esta congregación permite hacerse una idea de hasta qué punto las madrileñas comunidades de nación formaban parte habitual de la vida económica y política, lo que lleva a considerar su dimensión cultural: es decir, qué imagen tenían de sí estas comunidades, y qué imagen tenían unas comunidades de otras. Las fuentes manejadas no fueron pensadas para dar este tipo

Compañía de Jesús, expulsada en 1767, y que planeaba concentrar los hospitales de nación y otros particulares en la capital para agregarlos al general. Esto indica que se estaba poniendo en marcha una política hospitalaria, que en mi opinión no puede ser ajena a la política social que los ilustrados impulsaron tras el motín de 1766.

122 ACSFN, Libros de Acuerdos, referencia en 23-VII-1770, ff. 225v-227. Una nueva referencia a ello y también a una oferta de comprar toda la iglesia, casa y parcela congregacionales por parte del vecino, el aragonés conde de Atarés, en 23-VIII-1772, ff. 239v-242.

${ }^{123}$ Referencia en ACSFN, Libros de Acuerdos, 23-VIII-1772, ff. 239v-242.

${ }^{124}$ El marqués de Cañizar, y desde 1740 conde de Luna, era José Bardají Gurrea Urriés. En cuanto al conde de Aranda, sabemos que cuando su padre, el anterior conde de Aranda, Buenaventura Pedro Abarca de Bolea, murió el 2-XII-1741, fue nombrado albacea testamentario su sobrino, Gabriel Pío Funes Villalpando, conde de Atarés. Entonces Aranda se llevaba muy mal con Pedro Rodríguez Campomanes, fiscal del Consejo de Castilla. Todo según Fichoz, registros núm. 035265 (José Bardají Gurrea Urriés); núm. 008212 (Buenaventura Pedro Abarca de Bolea), núm. 000003 (Pedro Pablo Abarca de Bolea) y núm. 014885 (Gabriel Pío Funes Villalpando). No sé si el Atarés vecino de la iglesia era este o su sucesor, con lo que podía ser o primo o sobrino del entonces presidente del Consejo de Castilla. De todos modos, los cuatro eran parientes.

125 Olaechea Albistur, Rafael: El conde de Aranda y el «partido aragonés», Zaragoza, Universidad de Zaragoza, 1969. 
de información, pero la dan: son referencias a las otras congregaciones, casi siempre indirectas, que constatan una relación habitual, prácticas similares y sobre todo una visión recíproca común, que podríamos llamar en cierto modo institucional, difícil de percibir de otro modo. Hay que advertir contra cualquier anacronismo: tratamos de congregaciones de nacionales en una monarquía absoluta y el término en la historiografía actual tiene connotaciones distintas, asociadas al Estado nacional, a las comunidades autónomas o al federalismo.

Hecha esta aclaración, las referencias muestran palpablemente a qué llamaban «nacional» unos nacionales como los navarros en el Madrid del siglo XVIII, y en qué medida el término aludía a comunidades cuyos miembros, para hacer negocios o conseguir poder, buscaban ser vistos como distintos a los de otras recurriendo a argumentos de orden político, jurídico e incluso lingüístico.

En 8-VII-1736 en junta general se reconocía que

«...todas las congregaciones nacionales establecidas en esta corte hacen anualmente honras formales por sus difuntos, y que la nuestra las reduce a dar 300 reales de vellón por cien misas al sacristán mayor [del convento de Trinitarios Calzados] con independencia de la cantada que se celebra en el altar de San Fermín cuando se muere algún congregante y de la rezada que según nuestras loables constituciones hace decir cada uno de los señores congregantes...».

Era necesario hacer «... una memoria de lo que llevará el convento por poner el túmulo, decir la misa cantada y bajar la comunidad a cantar la vigilia ...», y un congregante comunicó que la había hecho ya

«... con tres [memorias] que pedí a las [congregaciones] de los vizcaínos, riojanos, castellanos y leoneses, ...»126.

Este texto se refiere a las otras congregaciones: muestra que se conocían unas a otras, tomaban referencias mutuas, y que había otras comunidades nacionales, además de la de la Rioja y la de San Ignacio de Loyola, aquí identificada sólo con los vizcaínos.

Para 1744 tenemos referencia de que un recurso parcial para mantener al capellán de la nueva iglesia eran las limosnas de las misas de difuntos congregantes (calculando que morían dos por año aproximadamente), «...como lo practican en distintas congregaciones de esta corte ...» ${ }^{127}$, lo que evidencia una práctica piadosa común a todas ellas. Nuevamente en 1755 un socio expone «... a la junta el modo que observan para las cobranzas otras congregaciones, y especialmente la del Sr. Santiago [de gallegos]...» ${ }^{128}$. En este caso la práctica que se pretende compartir es administrativa.

126 ACSFN, Libros de Acuerdos, 8-VII-1736, ff. 396r-399v.

127 ACSFN, Libros de Acuerdos, 10-V-1744, ff. 448r-452v, la cita en f. 450v.

128 ACSFN, Libros de Acuerdos, 31-VIII-1755, ff. 36-49, el texto en f. 47. 
En 1758, estando enfermo el rey (que para entonces ya era el prefecto de la congregación) y considerando hacer procesión y rogativas por su salud, deciden no hacerlo

«[...] atendiendo a que otras congregaciones nacionales no saldrían en procesión según noticias que se procuraron tomar, [y] resolvió esta junta que no se hiciese por la nuestra esta novedad, mayormente cuando no se encontraba exemplar $[=$ caso antecedente $]$ en los libros en iguales casos, pero que sin embargo se estuviese a la vista de lo que practicasen otras congregaciones ...».

No obstante se celebró misa en la iglesia, a la que concurrieron muchos congregantes $^{129}$. La importancia del texto, sin embargo no está en que dice si hubo procesión o no, sino en que muestra que las congregaciones «se miraban» unas a otras, mantenían conversaciones, actuaban en función de lo que hacían las demás.

Los congregantes de San Fermín tuvieron más relación con la congregación de aragoneses, llamada de Nuestra Señora del Pilar, al menos por razones patrimoniales, ya que cuando el congregante Francisco Miguel Goyeneche, conde de Saceda, donó la casa y hacienda de Pozuelo del Rey en 1745, una parte de la venta había de darse a los escolapios en Madrid para un nuevo colegio, y otra a la aragonesa. Goyeneche lo daba todo a la congregación

«...con tal que siempre y cuando se verificase que los Padres de la Esquela Pía hiciesen nueva fundación en los barrios del Barquillo o sus inmediaciones se les había de dexar por la congregación las dos partes de la tercera de valor líquido en que se vendiese la $d[i c]$ ha. casa, y la otra parte de la tercera por el dorado del retablo de N[uest]ra. S[eño]ra. del Pilar de Zaragoza que se venera en su capilla del Hospital de la Corona de Aragón de esta corte, que llaman de Monserrate»130.

Doce años después, en 1757 se reconoce que la donación se había hecho a favor de la Congregación de Nuestra Señora del Pilar,

«sita en la iglesia de Monserrat de la plazuela de Antón Martín, para ayudar a dorar el retablo, que también lo está ya»131.

En resumen, un $33 \%$ de la venta de la casa se daba a los escolapios de Madrid (dos tercios) y al retablo del Pilar de la congregación aragonesa en Madrid (un tercio), lo que apunta a que el donante navarro, que desde luego tenía familiares en Aragón, se sentía vinculado al viejo reino y que quizás pudo haber estudiado en un colegio de escolapios. Pero lo más importante del texto es que

129 ACSFN, Libros de Acuerdos, 17-XII-1758, ff. 93-94.

130 ACSFN, Libros de Acuerdos, 30-V-1746, ff. 469r bis-474r, el texto en ff. 470v-471r.

131 ACSFN, Libros de Acuerdos, 23-X-1757, ff. 78-79, el dato en f. 78; y 16-VII-1757, ff. 8392, el texto en f. 87. 
atestigua una relación económica con la Congregación de Nuestra Señora del Pilar, que tenía su sede, con las de los catalanes y los valencianos, en la iglesia y hospital de Montserrat.

Como la congregación aragonesa iba a recibir dinero de la casa, debió seguir el asunto, y años después, en carta de 22-IX-1775, escribía a la de San Fermín interesándose por el estado de la venta aludiendo a otra carta anterior remitida en 20-VII-1758, según la cual en ese momento la Congregación del Pilar celebraba juntas, tenía su sede «en el Real Hospital de Nuestra Señora de Montserrate». Tenemos datos biográficos para dos de los tres aragoneses intervinientes ${ }^{132}$, y es del mayor interés observar que ambos compartían oficios en la misma caballeriza de la Casa real, en que también estaban otros congregantes navarros ${ }^{133}$. Los navarros y aragoneses que se escribían probablemente se conocían. El recibo por la venta de la casa de Pozuelo entregado a la congregación de Nuestra Señora del Pilar se fechó el 17-VII-1786 y se entregó a la Congregación del Pilar ${ }^{134}$.

Desde 1755 el monarca, patrono ya de la congregación de San Fermín y probablemente también de otras congregaciones nacionales madrileñas, empezó a llevar un control de su actividad. Se entraba en una etapa más intervencionista en que el Estado español, ya reestructurado y con más medios que a principios de siglo, reemprendía un largo período de reformismo político: en esos años también se intentaba la reforma fiscal, se iba aplicando el concordato de 1753, y se estaban introduciendo controles en la vida económica municipal a través de la Contaduría de Propios y Arbitrios. Pues bien, en 1764 el secretario de la de San Fermín afirmaba que

«El Alcalde de Corte Don Francisco Granados me pidió nuestras constituciones y cuentas de un quinquenio, y habiéndome informado que era orden general para todas las congregaciones pasé a dar parte [...] y me dijo S. E. que se siguiese la práctica de otras nacionales, $[\ldots .$.$] y supe que en efecto se habían presentado las$ cuentas de algunas congregaciones $[\ldots] \gg 135$

132 El hermano mayor era entonces el marqués de Ariza. La aludida carta de 22-IX-1775 la firmaban dos congregantes de la del Pilar: D. Pedro de Cistué y D. Benito Lamarta; ACSFN, Libros de Acuerdos, 28-VII-1776, ff. 276-280.

${ }_{133}$ El marqués de Ariza era Joaquín Palafox Rebolledo (1702-1775), marqués de Ariza, grande de España y caballerizo mayor. Pedro Cistué Coll, luego barón de Menglana, entonces era caballerizo de la reina (Fichoz núms. 04054 y 017958).

${ }_{134}$ Entonces era tesorero de la congregación el marqués de Villalópez; se mencionaba como Real Congregación «fundada en su capilla de la Iglesia del Real Hospital de la Corona de Aragón de esta Corte»; ACSFN, Libros de Acuerdos, 23-VII-1786, ff. 330v-335v, el texto en f. 332. El secretario de la Congregación de Nuestra Señora del Pilar en 1802 era D. Francisco de Assín, quien, despistado, en oficio de 27-VIII-1802, preguntaba si la casa de Pozuelo se había vendido; ACSFN, Libros de Acuerdos, 8-VIII-1803, ff. 430-432, la referencia en f. 431.

135 ACSFN, Libros de Acuerdos, 22-VII-1764, ff.176-179, el texto en f. 177. El protagonista era el castellano Francisco Sancho Granado (1716-1778), antiguo colegial mayor y oidor de la 
La referencia muestra que para entonces estas congregaciones formaban un conjunto que merecía atención política, aunque ésta consistiera sólo en asegurarse que todas estaban en situación regular, llevaban sus cuentas en regla y contaban con medios para desarrollar sus funciones, lo que puede que no sucediera con todas. Cuando el tribunal del rey actuaba así por fuerza tenía en cuenta, de modo que ignoramos, los grupos de inmigrantes que albergaban.

Una cuestión específica del mayor interés es saber si la relación que la navarra Congregación de San Fermín tuvo con la vasca Congregación de San Ignacio de Loyola fue distinta de la que tuvo con otras. Las evidencias disponibles muestran que así fue: pero fue más de vecinos y semejantes que de iguales. Había motivos para ello. A reservas de un análisis más preciso que aquí no puede hacerse, todo parece indicar que en el largo plazo las emigraciones vasca y navarra hacia el sur castellano desde por lo menos el siglo XVI fueron parecidas en ritmo, y que su éxito en los negocios y en el servicio al rey, ocupando puestos clave de la administración real, también fue parecido. Ya se ha hecho referencia a la poderosa posición que navarros y vascos acabaron ocupando en Cinco Gremios Mayores de Madrid, y de hecho en el siglo XVIII la congregaciones de San Ignacio y San Fermín reunían a dos de las principales élites mercantiles y funcionariales de la monarquía en Madrid, amén de las Indias y otros lugares.

La relación de nación a nación de los congregantes navarros con los vascos se muestra cuando los primeros, en junta particular de 31-VII-1746 acordaron para preparar la inauguración de la nueva sede con una procesión que había de tener lugar el 24 de septiembre, que

«... para obviar los inconvenientes y disputas que suelen ofrecerse en la concurrencia de unas comunidades con otras sobre preferencia o lugar señalado en los actos públicos como lo es el de la procesión, para que no llegase el caso de que la Congregación de S[a]n Ignacio de Loyola (q[u]e es la única a quien se ha de convidar por nacional) pueda pretender lugar señalado con separación o distinción en la procesión, se acordó (...) que (...) todas las funciones que se le ofrecieren se hagan sin guardar formalidad alguna de congregación ni distinción ...»

tal y como se hacía con todos desde $1684^{136}$. Que el protocolo procesional se suprimiera para no tener conflicto con la congregación vasca muestra a la vez que era ella, y sólo ella, la invitada a la ceremonia "por nacional». No sabemos si las demás iban a asistir también a ceremonia piadosa tan señalada, pero el dato tiene menos importancia que el del trato preferente que se daba a la de San Ignacio.

\footnotetext{
Chancillería de Valladolid, que fue alcalde de Casa y Corte entre 22-X-1755 y 30-X-1765; luego fue miembro del consejo de Órdenes Militares y vocal de la Junta General de Comercio y Moneda (Fichoz, núm. 002584).

${ }^{136} \mathrm{El}$ texto en ACSFN, Celebraciones, exp. 5-4.
} 
Por otro lado en la edición de 1761 de las constituciones de la congregación de San Fermín se alude nuevamente a la procesión de 1746, y se afirma que se hizo

«... con asistencia de la Nobilísima Congregación de San Ignacio; circunstancia que realzó notablemente la solemnidad, estrechando más el antiguo vínculo e ilustre alianza con que la naturaleza, el terreno y el idioma unió aquel apreciable principio y antemural de las Españas; ...»137

El texto parece referirse a ambas comunidades, vasca y navarra y reconoce que existían vínculos de geografía e idioma que otorgaban a ambos grupos de congregantes el carácter de cabeza de «las Españas». Es un dato interesante, pero además yo destacaría algo que el texto también da a entender con toda claridad: que no eran sólo vínculos ancestrales los que les vinculaban, sino la conciencia sentida de un destino de liderazgo, de éxito colectivo. $Y$ es que en realidad esto justamente, el éxito social, era lo que vascos y navarros creían compartir sobre todo al asistir juntos a la procesión navarra en Madrid. Más aún, en un borrador manuscrito de las constituciones navarras de 1761, hecho previamente por un congregante cuyo nombre no conocemos, se alaba el nombre de Navarra,

«... que la escabrosidad del terreno, el polvo de la antigüed[a]d y natural cortedad [ = recursos] de los navarros [h]abían tenido hasta entonces casi encarcelado en los antiguos confines de Basconia ...»138

testimonio de que, en el imaginario del redactor, existía una comunidad navarra originaria surgida de una Basconia romana que abarcaba ambos territorios. La comunidad había alcanzado su esplendor; y ambos elementos imaginados, un territorio común y un destino manifiesto de éxito social, hermanaban también a los congregantes vascos y navarros en el siglo XVIII.

Hay otros datos que prueban esta relación. Cuando en 1715 los vascos fundaron su congregación nacional, tomaron como referencia los estatutos de

\footnotetext{
137 Constituciones de la Real Primitiva Congregación Nacional de los Hijos y Descendientes del Nobilíssimo y Fidelíssimo Reyno de Navarra que residen en esta Imperial Villa de Madrid, fundada en el año de 1684 (...), Madrid, s.e., 1761, Reedición facsimilar, Real Congregación de San Fermín de los Navarros, 1989, pág. 6. El documento original manuscrito, aprobado por el Consejo de la Cámara de Castilla, firmado y sellado por el rey en San Ildefonso, 4-VIII-1760, en ACSFN, Constituciones, exp. 8-9. Se conserva un primer borrador, con un prólogo largo que no llegó a publicarse, que suscitó gran polémica dentro de la congregación porque cuestionaba la veracidad de la reliquia de san Fermín, que custodiaban los monjes trinitarios calzados que acogían a la congregación, en detrimento de la que había en la catedral de Pamplona. En ACSFN, Constituciones, exp. 8-12. La polémica es de gran interés.

${ }_{138}$ Del borrador citado, sin foliar, en ACSFN, Constituciones, exp. 8-12.
} 
la de San Fermín ${ }^{139}$, y en diciembre de 1773 la vasca Congregación de San Ignacio de Loyola invitó a la de San Fermín a la celebración de la primera fiesta de la colocación del Santísimo Sacramento en su iglesia de la calle del Príncipe, acto que iba a tener lugar el 27-IX-1774; la de San Fermín aceptó la invitación y acordó enviar una diputación de nada menos que siete personas ${ }^{140}$.

Un último elemento a considerar es la lengua. Una parte de los emigrantes vascos y navarros compartían el vascuence como lengua materna y diferenciadora, y esto era una característica que los distinguía fuertemente frente a terceros. Los miembros de las casas navarras, los que emigraban y los que no, hablaban vasco en su infancia, y emigraran luego o no, como han demostrado Imízcoz $^{141}$ y otros historiadores, pero de su uso en Madrid los testimonios son pocos e indirectos. El único seguro es muy tardío, y probablemente tiene que ver con cambios que se habían producido en la composición social de la congregación. En 1804 la junta de San Fermín aceptaba el regalo de un ejemplar del libro del reverendo don Pedro Pablo de Astarloa Apología de la lengua vascongada, recién editado, encuadernado en pasta ${ }^{142}$; y en 1808 la junta de la congregación, sorprendentemente, hizo explícita las dos cualidades de «bascongado» (aquí: vascoparlante) y navarro que el capellán de la congregación debía tener para ser elegido:

«Habiendo concurrido diferentes dudas sobre la descendencia y nombramiento de los capellanes para esta iglesia de San Fermín de los Navarros, se determinó por punto general que fuesen preferidos y nombrados para capellanes los que fuesen bascongados y del obispado de la diócesis de Pamplona, y aunque se presentase solicitud por un presbítero que fuese navarro y careciese el tal del idioma bascongado, sea preferido el que fuese del obispado de Pamplona y posea dicho idioma bascongado, todo lo cual lo determinó la junta por [ser] punto general y esencial ser [sic] indispensable para acudir a prestar los auxilios espirituales a los Vasco Navarros ${ }^{143}$ que acudan a los hospitales generales y $[=$ para que $]$ no carezcan de dicho espiritual auxilio» 144 .

139 Constituciones de la Real Congregación Nacional de Beneficencia de los bijos y originariosde las tres muy nobles y muy leales provincias de Cantabria (...). Adicionadas e impresas en Madrid en el año de 1761. Reimpresas en Madrid, F. de Serra y Madirolas, 1852.

140 ACSFN, Libros de Acuerdos, 21-XII-1773, ff. 256v-258.

${ }^{141}$ Imízcoz, José María, y GuERrERo, Rafael: «A escala de Imperio. Familias, carreras y empresas de las élites vascas y navarras en la Monarquía borbónica», en J. M. Imízcoz (dir.): Redes familiares y patronazco. Aproximación al entramado social del País Vasco y Navarra en el Antiguo Régimen (siglos XV-XIX), Bilbao, Universidad del País Vasco, 2001, pp. 175-202.

142 Astarloa, Pedro Pablo de: Apología de la lengua bascongada, ó ensayo crítico filosófico de su perfección y antigüedad sobre todas las que se conocen : en respuesta á los reparos propuestos en el diccionario geográfico histórico de España, tomo segundo, palabra Nabarra, Madrid, Gerónimo Ortega, 1803 Ed. facsímil, Valencia, Librerías París-Valencia, 1998. El dato en ACSFN, Libros de Acuerdos, 8-VIII1804, ff. 433-435v.

143 Es decir: los navarros vascoparlantes.

${ }_{144}$ ACSFN, Libros de Acuerdos, 14-XII-1808, f. 448. 
Otras declaraciones algo posteriores, de 1810, confirman que este criterio de que el capellán, además de ser congregante, debería hablar vasco para que pudiera auxiliar espiritualmente a los navarros vascoparlantes pobres que llegaban a los hospitales de la Corte, debió practicarse en todo el siglo XVIII ${ }^{145}$. El vasco se mencionaba así como un instrumento de comunicación, lejos del otro uso ideológico que los navarros nacionales, muchos de ellos vascoparlantes, le habían dado repetidamente: ser el testimonio de que había existido la citada Basconia romana a la que originariamente habían pertenecido vascos, navarros y franceses vascoparlantes. Poco importaban, para justificar esta interpretación del pasado, todos esos otros vascos y navarros que desde hacía siglos hablaban castellano. Poco importaba también que todo esto se expresara en castellano. Ser navarro al modo como lo eran los congregantes de San Fermín quería decir, más que ninguna otra cosa, ser castellano, español.

\section{COLOFÓN}

La aparición y desarrollo de Madrid como capital y sede de la Corte real desde fines del siglo XVI, fue posible por la llegada de reducidas diásporas de financieros, que durante unas décadas atendieron las necesidades de la monarquía y desaparecieron sin dejar apenas rastro, y sobre todo de grandes grupos migratorios procedentes de Castilla y del Norte peninsular. Por lo menos la mitad fueron gallegos, asturianos, «cántabros», «vizcaínos» y navarros, que formaron extensas y complejas redes sociales basadas en lazos de vecindad, linaje, amistad y comercio. Casi todos ellos acudieron desde el principio del período considerado o estaban allí ya. La otra mitad fueron castellanos, como ha demostrado Carbajo ${ }^{146}$.

Su desarrollo fue variable, y el éxito económico y social de sus individuos dependió de factores como la coyuntura económica, la política y la actuación individual y en grupo de sus componentes. El tiempo impulsó la aparición de redes horizontales, que abarcaron sectores económicos y administrativos enteros, y verticales, de miembros que formaron comunidades nacionales en torno a congregaciones, cofradías y hospitales. Una de las más importantes fue la de navarros, que desde fines del siglo XVII ante todo fue la expresión del triunfo

145 Representación del viceprefecto D. Martín Josef de Oser y el congregante D. Juan Josef de Azpíroz al ministro de Negocios Eclesiásticos, Madrid 21-III-1810, en ACSFN, Libros de Acuerdos, 13-III-1710, ff. 449-451, el texto en ff. 449v-451.

${ }_{146}$ Los datos primarios en CARBAJO ISLA, María: «La inmigración a Madrid (1600-1850)», en Revista Española de Investigaciones Sociológicas, no 32 (1985), pp. 67-100., cuadros XI-XIII, pp. 85-87, con muestras de cuatro parroquias (Santa Cruz, San Sebastián, Santa María y San Ginés) que recogen la procedencia regional de los inmigrantes para ciertos años: 1650, 1674, 1694, 1704-1713, 1714, 1734, 1750, 1780-1789, 1827-1836. Más detalle en CARBAJO IsLA, María: La población de la villa de Madrid: desde finales del siglo XVI hasta finales del siglo XIX, Madrid, Siglo XXI, 1987. 
social de sus componentes dentro de la monarquía, y que también tuvo fines piadosos, se ocupó de prestar asistencia social a los connaturales pobres, y mantuvo un espacio de sociabilidad y comunicación para sus miembros.

La existencia en la capital de una telaraña de redes sociales y cofradías piadosas y asistenciales conformó un auténtico crisol social que desde fines del siglo XVI generó intereses sociales enfrentados, identidades nacionales en parte definidas así por serlo frente a otras — usando factores diversos: fueros, naturalidad, lengua, actividad económica, religión-, y pugnas por ocupar parcelas del poder político que el rey distribuía y sus prebendas económicas o sociales. En un espacio así pertenecer a una cierta red clientelar, y no a otra, podía ofrecer ventajas importantes, incluso decisivas. Los navarros fueron de los más privilegiados.

Madrid se había convertido en el núcleo urbano mayor de la monarquía, la plaza donde se negociaban las necesidades financieras del Estado, la sede de la aristocracia cortesana y los grandes conventos, lo que determinó la aparición de un gran mercado de bienes y servicios y del principal centro financiero español. En ese contexto, el análisis del éxito de la comunidad nacional de navarros, de que aquí no se ha dado cuenta muy general, irá dando claves para entender qué factores actuaron a favor de unas y no de otras, y cómo estas redes fueron influyeron en desarrollo de la monarquía absoluta, el mercado madrileño y la vida política del Estado español. 